\title{
LAS ARMADURAS SEGMENTADAS (LORICAE SEGMENTATAE) EN LOS YACIMIENTOS ROMANOS DE LA PROVINCIA DE LEÓN: UN ESTUDIO DE CONJUNTO
}

\author{
JOAQUÍN AURRECOECHEA FERNÁNDEZ ${ }^{1}$ \\ Universidad de Málaga
}

\section{RESUMEN}

Se estudian los abundantes restos inéditos de loricae segmentatae procedentes de la provincia de León, donde se documentan todas las variantes de estas piezas conocidas hasta el momento. Los yacimientos leoneses han proporcionado la cronología final más avanzada de todo el Imperio respecto a las armaduras "Corbridge" y a las corazas "Newstead", dato corroborado en diversas excavaciones y que deberá ser tenido en cuenta a la hora de fechar estas categorías en el futuro.

\section{ABSTRACT}

We analyze the unpublished discoveries of loricae segmentatae from León province. In that territory, all the recognizable categories are attested. Sites from León offer the most advanced late chronology in the whole Empire, regarding armours to "Corbridge" and "Newstead" types, fact corroborated in diverse excavations. It will be necessary to consider when we date these loricae segmentatae in the future.

PALABRAS CLAVE: Armadura romana. Lorica segmentata. Legio VII gemina. León (España).

KEY WORDS: Roman armour. Lorica segmentata. Legio VII gemina. León (España).

\section{INTRODUCCIÓN}

Como en otros aspectos de la arqueología militar, Hispania ha sido una gran desconocida a nivel internacional respecto al mundo de las armaduras romanas. Las referencias a nuestra provincia en las investigaciones al uso son prácticamente inexistentes, a pesar de la constante aparición en nuestro suelo de restos vinculados con estos protectores, especialmente durante los últimos años. No obstante, el panorama científico está cambiando, debido a que los recientes descubrimientos efectuados en la provincia de León han dando un vuelco a dicha situación, convirtiendo nuestra zona en un referente imprescindible. La abundancia de materiales, la diversidad de las piezas constatadas y su cronología, asentada esta última sobre sólidas bases estratigráficas, nos per-

\footnotetext{
jaurreco@uma.es
}

miten realizar un completo trabajo de síntesis, como el que desarrollaremos a lo largo de estas páginas ${ }^{2}$.

El papel de la armadura es fundamental en cualquier imperio, pues se convierte en un elemento primordial a la hora de garantizar el éxito de los ejércitos en el campo de batalla. Balent $(1989,86)$ identifica dos aspectos comunes que afectaron a su fabricación a lo largo de toda la historia de la humanidad. El primero es dotar de flexibilidad a la armadura para permitir a su usuario la necesaria libertad de movimiento. En segundo lugar el peso, pues tiene que ser lo suficientemente ligera como para ser llevada sin cansarse, factor éste que no debe ir en detrimento de la protección que ofrecía ante las armas de los enemigos. Estos dos aspectos influyeron decisivamente en la evolución de la coraza romana, pues ésta es el resultado del compromiso entre movilidad y protección.

Tampoco pudo sustraerse la época romana a las pautas que marcan el progreso evolutivo de este tipo de armamento defensivo, pues dicho desarrollo está marcado por dos factores principales: determinismo técnico y cambio cultural. Los logros técnicos posibilitan la fabricación de armaduras con materiales más ligeros y resistentes, mientras que las implicaciones culturales obligan a la constante adecuación del arma frente a los nuevos enemigos que van surgiendo y el equipo militar que estos últimos utilizan. De griegos, partos, sármatas y celtas tomaron prestados tanto los modelos como la tecnología para la fabricación de estas piezas (Bishop; Coulston, 1993, 195), hasta el punto de que en el siglo I gran parte del equipo defensivo del soldado romano derivaba de aquel empleado por sus enemigos. A partir de este armazón cultural, las corazas romanas fueron evolucionando hasta adquirir carta de naturaleza propia y alcanzar modelos originales, como la característica lorica segmentata.

Entre los distintos tipos de armaduras usadas por los romanos destacan cuatro categorías principales: la cora-

\footnotetext{
2 Dicho estudio se enmarca dentro de la Tesis Doctoral sobre militaria Romana del norte de la Península Ibérica que en la actualidad estamos realizando, bajo la dirección del Prof. A. Morillo Cerdán.
} 
za musculada, la cota de malla, la armadura de escamas y la segmentada. Junto a estas clases principales se encuentran otras más minoritarias, en algunos casos modelos híbridos de los mencionados anteriormente. Hay que tener en cuenta que la armadura no es un arma defensiva aislada, sino que forma parte de un sistema funcional que involucra cascos, escudos, tácticas defensivas y formaciones de batalla. Tampoco podemos olvidar que como complemento de estas piezas existían otros protectores que cubrían los miembros o las partes del cuerpo que no quedaban protegidas por las armaduras, así las grebas. El resultado fue que la armadura evolucionó en simbiosis con los otros elementos defensivos. Podemos hablar de una tendencia que persigue el equilibrio entre: la protección, la movilidad y el costo. La búsqueda de dicho equilibrio desembocó en la introducción de la lorica segmentata y en la simplificación formal de los especimenes. En el campo que nos ocupa, el concepto de evolución no implica la obsolescencia de los tipos de armadura más arcaicos, pues raramente los modelos cayeron en desuso. Unos y otros permanecieron en servicio de modo paralelo, aunque se constata la menor representación numérica de las categorías que se van quedando anticuadas. No podemos entender el mundo de las armaduras como algo unitario, pues aspectos tales como la capacidad industrial de cada legión, la disponibilidad de materias primas, la ubicación geográfica dentro del Imperio, la confortabilidad en determinados climas, o simplemente los gustos personales de los soldados que formaban las unidades militares, también dejaron su impronta en el diseño de estas piezas.

$\mathrm{Al}$ igual que otros objetos militares, el estudio de las armaduras romanas se basa en tres fuentes principales de conocimiento, cada una de ellas con sus propias limitaciones. Las fuentes literarias son sumamente parcas en el tema que nos ocupa, pues apenas nos ofrecen detalles sobre los tipos de corazas y los personajes que las portaban. Más nutrida es la evidencia iconográfica sobre estas piezas, la cual se divide entre la escultura oficial y la privada. El arte oficial posee un marcado sesgo propagandístico. En este contexto se suelen representar personajes notorios, como el emperador, vistiendo armaduras muy peculiares, como las ceremoniales o las destinadas a los desfiles. Mucho más rara es la plasmación de la tropa, y cuando ésta se lleva a cabo escasean los detalles realistas, pues tiende a una simplificación formal que subraya el símbolo frente a la forma. Los artistas que produjeron estas obras introdujeron sus propios convencionalismos artísticos y estilísticos, como bien puede ejemplificarse en la Columna de Trajano. Esta última obra fue la base de muchos estudios sobre el ejército romano, siendo solamente en tiempos recientes cuando se ha cuestionado su validez como fuente de conocimiento. En principio podríamos presuponer que la Columna nos narra con todo lujo de detalles las dos campañas dácicas del emperador (1002 y 105-6 d.C.), mostrándonos legionarios con armaduras segmentadas y a la infantería y caballería auxiliar con cota de malla y coraza de escamas. Este esquema de uso no fue tan rígido y más bien parece el producto de unos escultores que habitaban en la metrópolis de Roma y estaban poco familiarizados con las tropas fronterizas. Es muy posible que su única fuente de conocimiento directa fuera la proporcionada por las unidades de guardia en Roma, y que esta información parcial influyera decisivamente en los modelos que representaron. Aparte de este aspecto, la Columna está plagada de convencionalismos que limitan su interés. Algunos afectan al campo de las costumbres, como aquel que nos muestra a los legionarios realizando obras de albañilería o construcción mientras llevan puestas sus armaduras segmentadas (Robinson, 1975, 183), vestimenta poco apropiada como ropa de trabajo a menos que el soldado se encuentre en peligro inminente. Otros son de índole formal o dimensional, como la costumbre de reducir ostentosamente el tamaño de los escudos para poder mostrar mejor a las personas que se encuentran detrás de ellos (Bishop; Coulston, 1993, 21-22). Todos estos detalles demuestran que la plasmación exacta del equipo militar que portaban los soldados no era el principal objetivo de los artistas que trabajaban para el Estado. En contraste con la Columna de Trajano, el Trophaeum Traiani de Adamaklissi (Rumanía), levantado hacia el 108-09, muestra una menor uniformidad de equipo militar, lo que a priori le dota de mayor credibilidad. Para Bishop y Coulston (1993, 22) los artistas que trabajaron en él prestaron atención a los detalles, reflejando con precisión los distintos tipos de armadura conocidos gracias al registro arqueológico. Estos rasgos realistas y la exactitud técnica demostrada podrían significar la implicación directa en el trabajo de soldados o veteranos que aportarían su propia experiencia, motivo por el cual su estilo sería tan diferente al de otras obras coetáneas, como la mencionada Columna. En Adamaklissi podemos ver a legionarios con cotas de malla y armaduras de escamas, y no sólo con la clásica armadura segmentata. A pesar de lo expuesto, el monumento de Adamaklissi no puede sustraerse a determinados convencionalismos de estilo, como el consistente en representar las anillas de las cotas de malla mediante agujeros, si bien este aspecto está condicionado por el material empleado en la fabricación del Trofeo y la técnica usada para trabajar la piedra.

Desde el punto de vista de las fuentes arqueológicas podemos señalar unas cuantas premisas que afectan a nuestra parcela de estudio. La desigualdad de conocimiento entre las distintas áreas del Imperio no sólo produce una distorsión en cuanto a los mapas de distribución, sino que también favorece la extrapolación de 
datos originados en las zonas mejor conocidas, sobre todo Britania y en menor medida el limes renano-danubiano. La generalización de parámetros basados en entornos locales condiciona los estudios realizados en otros ámbitos geográficos distintos, pues suele caerse en la inercia de aplicar las pautas obtenidas en regiones mejor documentadas. Por tanto, la sobrevaloración de algunas provincias del Imperio, o los hallazgos espectaculares de ejemplares completos o en depósitos cerrados, como el archiconocido ocultamiento de Corbridge (Gran Bretaña), han desequilibrado nuestro conocimiento global sobre las armaduras romanas. Al mismo tiempo, dicho desequilibrio se ve fomentado por la sobreabundancia con que aparecen representados determinados tipos de armaduras, sobre todo las segmentadas. La mayor frecuencia de hallazgos materiales vinculados a las lorigas segmentadas no implica necesariamente un uso más extendido de las mismas frente a otras categorías, sino el superior deterioro de éstas. La abundancia con que aparecen los apliques decorativos o funcionales fabricados en cobre/bronce de estas armaduras, frente a la escasez de restos pertenecientes a los flejes de hierro de dichas corazas, avalan las incesantes reparaciones que eran necesarias para mantener la pieza plenamente operativa. De este modo, los persistentes hallazgos de lorica segmentata simplemente reflejan una menor vida útil de los componentes que la conformaban (Bishop; Coulston, 1993, 13).

\section{CARACTERÍSTICAS GENERALES DE LAS ARMADURAS SEGMENTADAS}

Entre los protectores corporales de la infantería romana, el prototipo mejor conocido es la lorica segmentata, si bien el nombre con el que la conocemos en la actualidad es de reciente acuñación, pues ignoramos como la denominaban los romanos (Robinson, 1975, 174. Harmand, 1986, 197). En los últimos años han proliferado las investigaciones sobre esta clase de armaduras, viendo la luz una serie de ensayos de conjunto que han hecho avanzar enormemente nuestro conocimiento sobre ellas (Bishop, 1998; 1999; 2002. Thomas, 2003).

La lorica segmentata ponía un evidente énfasis en la protección del hombro. Salvaguardar este punto débil era de vital importancia cuando se combatía con enemigos que usaban espadas largas, pues cuando el soldado se resguardaba tras su escudo era sólo vulnerable en los hombros y la cabeza (Connolly, 1991, 362). Si tenemos en cuenta que los cascos romanos se diseñaron para proteger la cabeza desviando los golpes hacia los hombros, nos daremos cuenta del sentido que tenía sobreproteger esa zona. Además, la curvatura de las placas de la lorica segmentata favorecía el desvío de los golpes directos sobre ella, lo que potenciaba su efectividad.
Se trata de una coraza formada por láminas de hierro articuladas sobre tiras de cuero, disponiéndose estas últimas en la cara interna. El conjunto se complementaba con una serie de accesorios de cobre/bronce que articulaban externamente las placas o servían para abrochar las distintas secciones de la misma. Dichos accesorios eran sumamente frágiles, lo que propiciaba su rotura, sobre todo si tenemos en cuenta su connivencia con las placas de hierro, no sólo más resistentes, sino proclives a la corrosión, lo que debilitaría las partes metálicas de bronce en contacto con el hierro (Rollason, 1961, 127-128). Junto a la lorica segmentata era casi obligado vestir una especie de camisa acolchada (thoracomachus; de rebus bellicis XV) que servía para evitar los roces producidos por el metal y sobre todo la abrasión en los hombros, donde se descargaba gran parte del peso.

Desde el punto de vista tipológico, las armaduras segmentadas se dividen en tres tipos básicos: "Kalkriese", "Corbridge" y "Newstead"; a los que hay que añadir una categoría híbrida relacionada ("Alba Iulia"; Bishop, 2002). Estructuralmente todas estas corazas están formadas por cuatro secciones: dos para los hombros y otro par para el torso.

Para analizar los restos conservados es necesario, en primer lugar, aclarar la estructura general de estas armaduras, para poder así encuadrarlos en las categorías pertinentes. La identificación de los fragmentos de corazas segmentadas es muy difícil, debido al precario estado de conservación de las placas de hierro que las conforman y a la escasa entidad de las piezas que a menudo se hallan. También hemos de tener en cuenta que el deterioro que sufren las distintas placas es diferente, siendo más fáciles de dañar en un combate la hombrera que las láminas de la faja, potenciando la reparación y recambio de determinadas piezas sobre otras. Asimismo, el tamaño de la placa es un factor a tener en cuenta a la hora de la conservación, por lo que suelen estar mejor documentadas en las excavaciones arqueológicas las placas más grandes, como la pechera o el peto. Más significativos para encuadrar los hallazgos de armaduras segmentadas dentro de una variante concreta son algunos de los accesorios de cobre/bronce que las complementan. El carácter funcional de estos elementos, pero aún más la morfología que los caracterizan, sirven para diferenciarlos del resto del equipo que portaban los soldados romanos. La mayoría de estos accesorios, como bisagras o discos troquelados, no cuentan con paralelos en ninguna de las otras categorías de objetos característicos del mundo militar. Asimismo, la evolución tipológica y temporal que sufrieron estas corazas tiene su exponente mas relevante en las diferencias que ostentan entre si estos apliques de bronce, lo que les convierte en una referencia imprescindible para clasificar los vestigios que han llegado hasta nuestros días. 


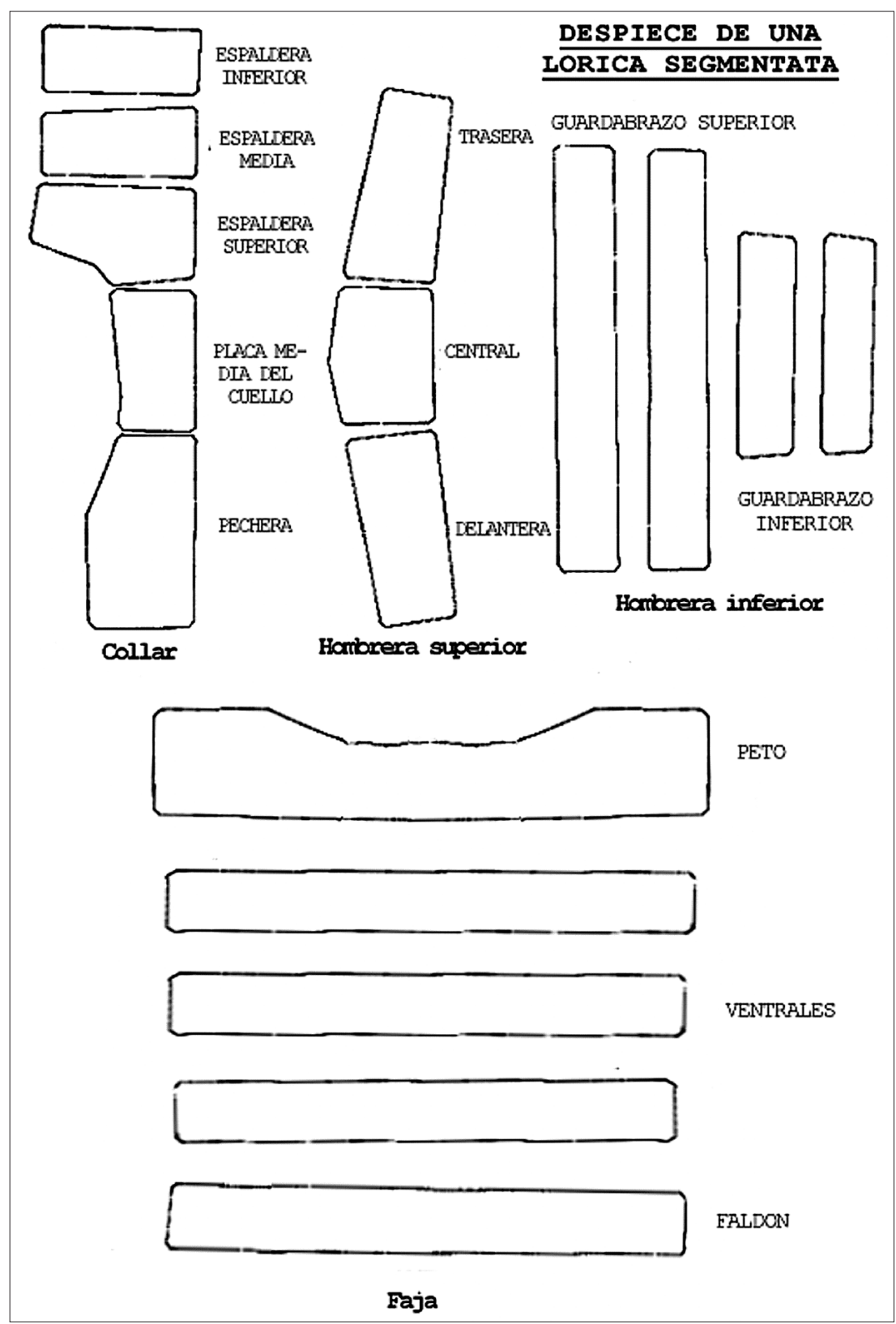

Figura 1. Despiece de una lorica segmentata con propuesta de nomenclatura para cada una de las distintas partes.

Para diferenciar las distintas placas que conforman las loricae segmentatae hemos procedido a denominarlas según una terminología propia, derivada en parte de las similitudes que presentan con las armaduras medievales (fig. 1). La elaboración de dicha terminología la consideramos un paso previo imprescindible, debido a la escasa uniformidad a la hora de denominar las distintas piezas integrantes de estas corazas en las investigaciones al uso. Sólo algunos trabajos de habla inglesa han intentado sistematizar este apartado $^{3}$, si bien los logros alcanzados han sido escasos. Siempre que ha sido posible hemos respetado la tra-

3 Entre ellos las obras clásicas de Robinson (1975) y Bishop (2002). 
ducción literal del término anglosajón ofrecido por Bishop en sus numerosos trabajos que sobre esta materia ha publicado en los últimos años (Bishop, 1998; 1999; 2002), como por ejemplo, la palabra collar para referirse a las placas del cuello. No obstante, Bishop sólo ofrece denominaciones específicas para los conjuntos o grupos de placas más significativos, dando nombre únicamente a las piezas individuales que él considera especialmente relevantes, como la pechera (breastplate, según el vocablo inglés). Sin embargo, nosotros hemos preferido profundizar aún más en la división de las placas, individualizando y dotando de denominación a todas las distintas partes susceptibles de ser identificadas en el registro arqueológico. Así, mientras en las publicaciones al uso sólo se menciona la hombrera superior e inferior, nosotros hemos aislado sus distintos componentes, a los que nombramos con términos individuales (por ejemplo, guardabrazo superior e inferior).

Todas las lorigas segmentadas, salvo las del tipo "Alba Iulia", constan de dos partes bien diferenciadas. La primera de ella está conformada por las placas que protegen la parte superior del tórax, es decir, el pecho y los hombros. Éstas se encuentran duplicadas para cubrir el lado izquierdo y derecho del cuerpo. Precisamente, las corazas "Alba Iulia" carecen de placas segmentadas en esta zona, siendo sustituidas por un peto de escamas. En el resto de las lorigas que estudiamos, la protección superior del tronco se articula en torno a las placas que bordean el cuello, las cuales conforman el collar, y las que cubren el hombro, divididas en hombreras superiores e inferiores. Todas las láminas del collar presentan un lado ligeramente curvo para adaptarse a la forma del cuello, teniendo en ese punto un pequeño saliente redondeado o escalón, para evitar los cortes del metal sobre la piel del soldado. Cuando su estado de conservación es satisfactorio, en el registro arqueológico son fácilmente identificables tanto la pechera (que se dispone sobre el pecho), como la espaldera, si bien en ocasiones esta última se divide en varias secciones que entorpecen la identificación de esta pieza. Tanto el collar como la hombrera superior están articulados por medio de bisagras, para facilitar su colocación sobre el cuerpo del soldado, siendo además las placas sobre las que recala un mayor anhelo decorativo, pues no sólo las bisagras adquieren perfiles que resaltan un carácter ornamental, sino que hebillas y discos troquelados potencian el efecto visual. La hombrera inferior, por su parte, no sólo carece de decoración sino que se sujeta únicamente gracias a las correas internas que la unen con la hombrera superior adyacente. Por regla general el perfil de todas las placas que cubren la parte superior del tronco es bastante recto, por contraposición a las que veremos a continuación.
La segunda porción está compuesta por las placas que circundan el abdomen, divididas en dos mitades curvas que se unen en el eje central del estómago y la espalda. Todas ellas conforman la faja, dividida está en tres secciones: la superior, cubierta con el peto; la zona media, donde se disponen las láminas ventrales; y la inferior, denominada faldón. El peto presenta en uno de sus lados la típica curva para adaptarse al cuello, así como el engrosamiento del perfil para evitar el corte en contacto con la carne del soldado. Por su parte el faldón cuenta con un engrosamiento similar, pues descansa directamente sobre las caderas del legionario. Todas las placas que conforman la faja son fácilmente reconocibles; en primer lugar por la amplia curvatura que las caracteriza y las dimensiones que ostentan, pues estas últimas son bastante mayores que las que cubren pecho y hombros; pero además porque cuentan con un número mayor de correas internas, lo que origina una superior cantidad de remaches.

\section{ARMADURAS DEL TIPO “KALKRIESE”}

Esta categoría de armaduras era totalmente desconocida en el panorama investigador hasta hace muy pocos años (fig. 2, 2). El descubrimiento de una pechera completa en el denominado Varusschlacht en Kalkriese (Osnabrück, Alemania) fue un echo definitivo para poder constatar la existencia de un nuevo tipo de coraza segmentada inédito hasta el momento. La importancia del hallazgo es destacable no sólo porque con él se logró documentar el tipo inicial de armaduras segmentadas usadas por el ejército romano, sino porque también retrotraía la cronología de estas corazas hasta la época de Augusto. Gracias a los diversos testimonios rescatados en Kalkriese (Schlüter, 1992, 307-402. Franzius, 1995, 69-88), sobre todo hebillas y bisagras, ha sido posible aislar un variado elenco de accesorios en cobre/bronce del que disponían estas loricae, facilitando la clasificación de objetos similares dispersos en otras excavaciones y que aún no habían sido identificados.

Hasta el momento se han logrado aislar dos variantes distintas (Bishop, 2002, 23-30). El tipo "KalkrieseA" está representado por la pechera aparecida en el yacimiento homónimo. En esta categoría, las placas del collar se unen con el peto mediante correas de cuero remachadas directamente sobre el hierro, a través de unas hebillas que se unen al cuero mediante pequeños remaches. La pechera y espaldera se articulan a la placa media del cuello mediante una bisagra simple o bilobulada, siendo importante destacar que durante el periodo augusteo no se han documentado las bisagras polilobuladas que popularizará el tipo "Corbridge". Otro elemento distintivo de las lorigas "Kalkriese-A" es el forra- 


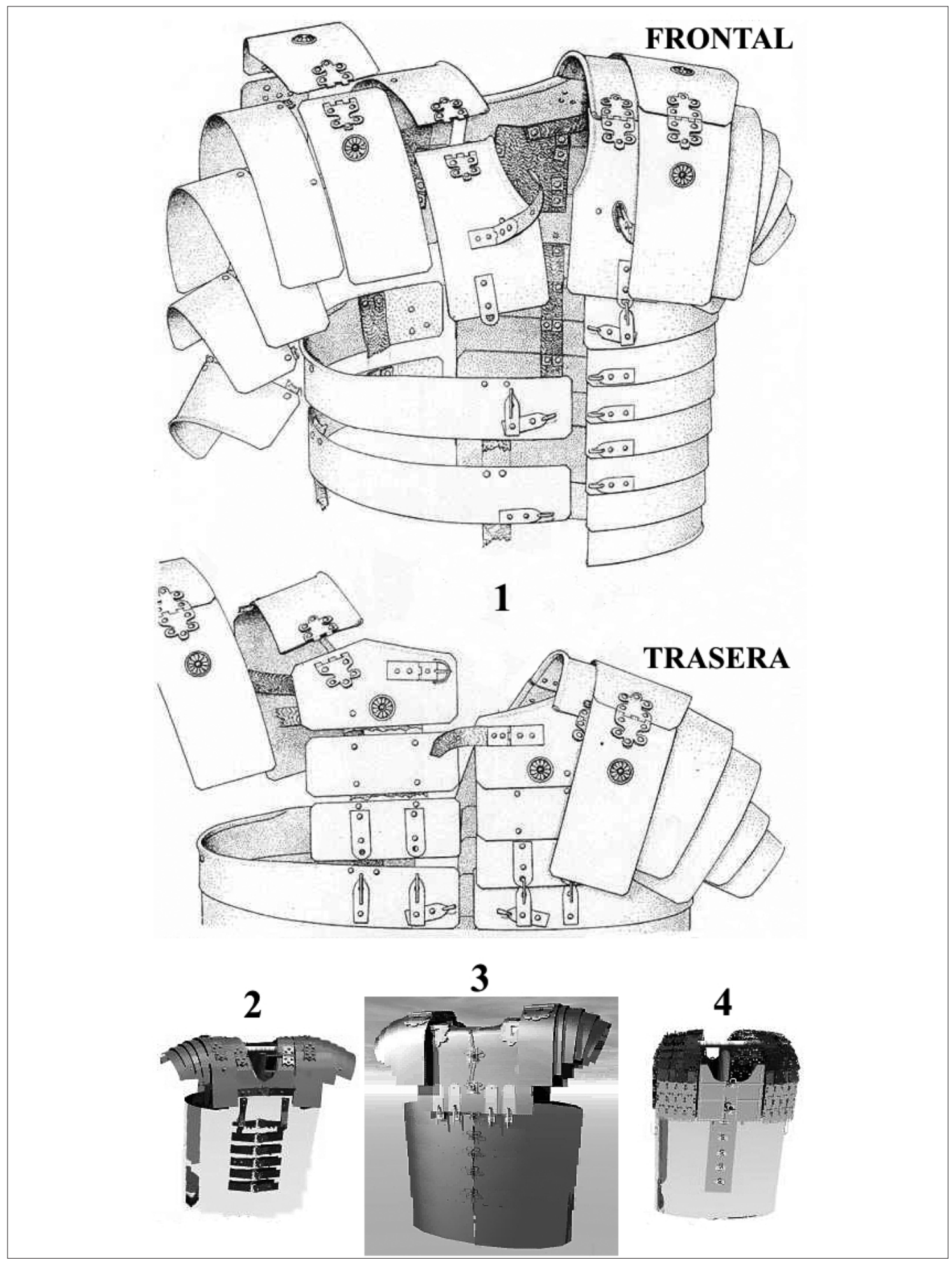

Figura 2. 1.- Esquema de armadura "Corbridge", según Robinson. Reconstrucción de los distintos tipos, según Bishop: 2.- "Kalkriese". 3.- "Newstead". 4.- "Alba-Iulia". 
do del perfil que rodea al cuello mediante una funda de cobre/bronce. El tipo "B" es similar al anterior, sólo que las correas de cuero no se remachan sobre el hierro sino que se insertan en las clásicas láminas charneladas de cobre/bronce. El enfundado de bronce que rodea el perfil del cuello es ahora sustituido por el engrosamiento de la lámina de hierro. Todas estas características prefiguran las que luego desarrollará el tipo "Corbridge".

Respecto a su cronología, se ha señalado una temporalidad que abarca desde el reinado de Augusto hasta el de Claudio (Bishop, 2002, 23-30). Podemos afirmar que ya estaba en uso durante el desastre de Varo (9 d.C.) y que continuó utilizándose, al menos, hasta la conquista de Britania en la década de los 40 del siglo I, como atestiguan los hallazgos de bisagras análogas a las aparecidas en Kalkriese en yacimientos como Chichester y Waddon Hill (Down, 1989, fig. 27). No obstante, en Dangstetten (Alemania) se han identificado algunos fragmentos adscritos a la variante "A" fechados en torno al 9 a.C. (Fingerlin, 1986, 136, lám. 371), conformando en la actualidad la datación más antigua para estas armaduras.

Sobre la forma de la faja o las hombreras, desconocemos casi todos los detalles, pues apenas han sido encontrados ejemplares adscritos a esta categoría. Se ha señalado una hombrera de Chichester como perteneciente a este tipo, si bien no puede afirmarse con certeza (Bishop, 1998, 10). Mas segura es la hombrera superior delantera de Vindonissa (Suiza) y el fragmento de faldón de este mismo yacimiento (Unz; Deschler-Erb, 1997, lám. 30, 615).

Los testimonios de este tipo de armaduras en la Península Ibérica, por el momento, son muy escasos. Aunque debido a la reciente identificación de estas corazas no podemos desdeñar la aparición de piezas similares en nuestro suelo durante los próximos años. En la actualidad se reducen a una bisagra descubierta en Iruña (Bishop, 2002, fig. 4.3, 1) y un par de ejemplares procedentes de Astorga. Las bisagras del tipo "Kalkriese" prefiguran las clásicas piezas insertadas en la categoría "Corbridge", si bien en la primera variante la forma del objeto es mucho más simple. Mientras que en el tipo "Corbridge" estas articulaciones cuentan con tres lóbulos claramente destacados, los goznes adscritos a la clase "Kalkriese" apenan insinúan un par de lóbulos dentro de la estructura rectangular de la pieza, siendo también comunes las piezas con remate apuntado. Es de destacar que en todos los especimenes hispanos los orificios en que se insertan los remaches están enmarcados por círculos troquelados, rasgo que se convertirá posteriormente en arquetípico de las bisagras del tipo "Corbridge".

El testimonio español más temprano es una bisagra apuntada descubierta en Astorga (Asturica Augusta), siendo su cronología augusteo-tiberiana y estando ads- critas a la fase campamental de dicho yacimiento, cuando era la base de la legio X gemina ${ }^{4}$. Se halla adscrito a las excavaciones de la Plaza de Calvo Sotelo, 10 (UE 2108) (fig. 3, 1), y pertenece a la categoría "F.i" de la tipología de Thomas (2003, 63). A pesar de las escasas piezas publicadas, cuenta con buenos paralelos fuera de nuestras fronteras datados en época augustea, así los especimenes de perfil apuntado de Kalkriese, Oberwinterthur (Alemania) y Strasbourg (Francia) (Thomas, 2003, 62-63, fig. 45, 6-8).

Procedente de las obras de cimentación de las Termas Menores de Asturica (c/ Padre Blanco, 7/11) (fig. 3,2 ) es otra bisagra relacionada con el tipo "F.ii" de Thomas, al igual que el espécimen de Iruña, inserto este último en el sector 1, UE 1001d del yacimiento (Filloy ; Gil, 2000, no 353). El gozne bilobulado de Iruña ha sido publicado en un par de ocasiones pero sin realizar un estudio exhaustivo, por lo que desconocemos el material asociado, si bien los autores ofrecen una cronología de la segunda mitad del siglo I al siglo II. Dicha datación ignoramos si pertenece al contexto estratigráfico o si está relacionada con la cronología relativa de la pieza. El ejemplar de Astorga se fecha en las postrimerías de la primera centuria. Entre los paralelos aducibles en el estado actual de la investigación, contamos con uno casi exacto en Chichester, fechable en los años 40 del siglo I (Down, 1989, fig. 27.5, 80) y otro descubierto en Kaiseraugst (Suiza), datado en el 70/75 d.C. (Thomas, 2003, 63, fig. 46, 3). Dichos paralelos confirmarían que las bisagras que tratamos pertenecen al grupo de los accesorios tardíos dentro de esta categoría de armaduras, pues piezas similares no aparecen ni en el yacimiento de Kalkriese ni en los campamentos del limes de principios del siglo I, donde por el contrario son muy abundantes las bisagras apuntadas.

\section{ARMADURAS DEL TIPO "CORBRIDGE"}

De entre todas las categorías de armaduras segmentadas el tipo "Corbridge" es el más conocido (fig. 2, 1). Esta circunstancia no sólo deriva del hecho de que el

\footnotetext{
4 Las interpretaciones cronoestratigráficas de los yacimientos leoneses que ofrecemos en este trabajo están basadas en las investigaciones, aún inéditas, desarrolladas por D. Victorino García Marcos y el Prof. Ángel Morillo en el marco del proyecto del Ministerio de Educación y Ciencia (HUM2006-00534): "Campamentos romanos en Hispania: análisis diacrónico de las estructuras defensivas". También hemos tenido acceso al artículo en preparación: "Legio y Asturica Augusta. Análisis comparativo de la secuencia cronoestratigráfica de dos yacimientos de la Asturia Augustana”, del Prof. Morillo. Desde aquí queremos agradecer la ayuda prestada por estos investigadores para la elaboración de las precisiones cronológicas.
} 


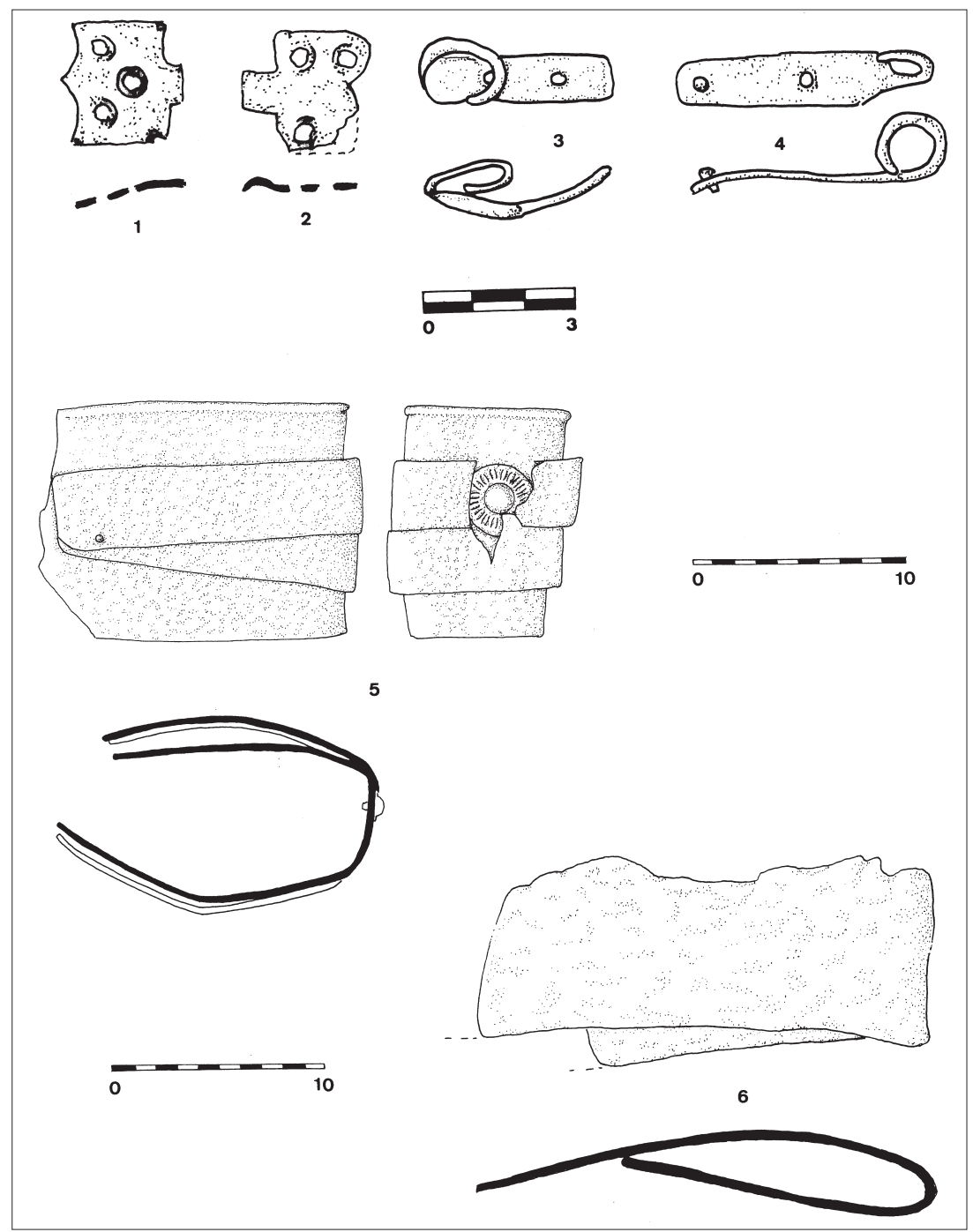

Figura 3. 1 y 2.- Bisagras "Kalkriese" de Astorga (1.- Calvo Sotelo y 2.- Padre Blanco). 3 a 7.- Restos "Corbridge" de León (3.- La Palomera, 4 a 6.- La Praviana).

famoso ocultamiento de material militar efectuado en Corbridge estuviera compuesto en su mayoría por corazas de esta clase, sino también porque los restos de estas lorigas se han prodigado en muchos asentamientos legionarios, hasta el punto de ser un descubrimiento común que goza de una amplia dispersión geográfica. La abundancia de vestigios relacionados con el tipo "Corbridge" está en relación directa con la fragilidad de sus accesorios elaborados en cobre/bronce, que son los que más se encuentran en las excavaciones. Aunque los distintos tipos de loricae segmentatae estuvieron en uso durante un periodo de tiempo similar, existe una evidente desproporción numérica entre los hallazgos de una categoría u otra. El rápido deterioro de los elementos broncíneos y su mayor presencia en la categoría de coraza que tratamos, pues las armaduras "Kalkriese" y "Newstead" emplean un número menor de estos accesorios, justifican la importante representación en el registro arqueológico del tipo "Corbridge".

Robinson (1975, 177-180) distinguió tres subtipos diferentes, los cuales han sido mantenidos por los investigadores sucesivos a pesar de los nuevos hallazgos. Diferenciar unas variantes de otras, cuando sólo se hallan fragmentos de la armadura, es una labor imposible, pues la pauta entre unos y otros suele ser determinados elementos que sirven para abrochar externamente las placas. La categoría "Corbridge-A" está definida por la unión entre la pechera y el peto, que se realiza 
mediante sendas hebillas, probable reminiscencia del tipo "Kalkriese". Por el contrario, en las corazas "Corbridge-B/C" dichas placas se abrochan mediante presillas, de forma que en la pechera se sitúan unas láminas perforadas en las que encajan los ganchos ubicados en el peto. Este método de presillas prefigura el modo de ensamblaje habitual en el posterior tipo "Newstead", por lo que parecería confirmarse una evolución cronológica que comienza con las "Corbridge-A" y termina con las "Corbridge-B/C". La distinción entre los subtipos "B" y "C" es más sutil, pues mientras en el primero las láminas perforadas son de bronce, en el segundo están fabricadas con hierro.

Junto a los accesorios que las caracterizan, según Robinson existen otros rasgos distintivos que nosotros ponemos en tela de juicio. Entre ellos afirma que las dimensiones y la morfología de algunas placas varían entre las distintas subcategorías, así por ejemplo la pechera en las "Corbridge-B/C" es ligeramente mayor, si bien creemos que esta circunstancia puede estar relacionada con diferencias de talleres que sería necesario aislar y estudiar en profundidad. Dichas disparidades podrían deberse simplemente a la forma de trabajar de diferentes armeros, e incluso la distinción entre los subtipos "B" y "C" podría ser ficticia basándonos en este razonamiento, como recientemente ha postulado Bishop (2002, 36). Otro rasgo diferenciador expuesto por Robinson y relacionado con lo expuesto, es el número de placas que conforman la faja, siendo éste ocho en las "Corbridge-A" y siete en las "B/C". Finalmente, Robinson señala otro criterio estilístico basado en los elementos de cobre/bronce que portan estas armaduras, si bien creemos que establecer razonamientos de esta clase es una apuesta muy arriesgada, debido a que las discrepancias entre unos y otros puede deberse a razones geográficas, la experiencia del artesano, la premura en la fabricación, o simplemente a modas asociadas a distintas unidades, entre las muchas razones que podríamos aducir. Para Robinson, estos accesorios estarían mucho mejor rematados y con perfiles más definidos en las "Corbridge-A", para posteriormente irse simplificando en las "Corbridge-B/C". De este modo, las bisagras lobuladas que articulan collar y hombrera superior tendrían en el subtipo "A" unos lóbulos simétricos parecidos a volutas, separados y perfectamente perfilados, a menudo con una perforación triangular en la zona próxima a la charnela; por el contrario en las variantes "B/C" las bisagras son más estrechas, los lóbulos apenas se destacan de las placas y adquieren un perfil similar a una cruz de brazos redondeados (Robinson, 1975, 180).

Siguiendo con los complementos en cobre/bronce de las armaduras que tratamos, aparte de las charnelas lobuladas, contamos con otro elemento característico que define a las loricae "Corbridge", como son los dis- cos decorados mediante la técnica del repujado. Discos y bisagras lobuladas conforman los elementos más reconocibles de este tipo de armaduras, aquellos que permiten detectar su presencia en los asentamientos militares, pues los flejes de hierro raramente se conservan hasta un grado que puedan ser identificados como pertenecientes a un grupo u otro. Igualmente representativas, pero más difícil de aislar en la documentación arqueológica, son las presillas caladas que hacen de pieza "hembra" para alojar los ganchos de la faja, pues su similitud con otros objetos de la vida cotidiana romana hace que no puedan ser reconocidos, a no ser que aparezcan asociados a otros restos de corazas. Por el contrario otros accesorios realizados en aleación cobre/bronce, como los broches charnelados con hebillas, las placas charneladas para correas o los ganchos, están presentes tanto en el tipo "Corbridge" como en el "Newstead".

El origen de las armaduras "Corbridge" se ha fijado en un momento indeterminado de la etapa tiberio-claudia (Bishop, 1998, 11). Poco más podemos especificar sobre la fecha concreta de su adopción, salvo su amplia presencia entre los contingentes armados que utilizó el emperador Claudio para la invasión de Britania en el año 43 d.C. Los testimonios de estas loricae se prodigan a medida que avanzamos en el tiempo, estando ampliamente constatados durante la dinastía flavia, como por ejemplo en Gamala (Israel) (Bishop, 2002, 31). Mucho más oscura es la última fecha de utilización de estas piezas defensivas. Su presencia en el Waffenmagazin de Carnuntum (Austria), depósito en el que se localizaron lorigas "Corbridge" y "Newstead", por lo que se ha considerado adscrito a una fase de transición entre uno y otro tipo, abalaría su postrero uso hacia la mitad del siglo II, aunque debemos tener en cuenta que la categoría "Corbridge" está considerada como la que tuvo una vida más dilatada frente a sus compañeras (Bishop, 1998, 12). Como tendremos ocasión de comprobar, los hallazgos de León ponen en tela de juicio la cronología final asignada por Bishop, demostrando que el tipo perdurará mucho más de lo que se podía prever en un principio.

El testimonio más antiguo del tipo "Corbridge" en el campamento de León es un gancho documentado en la UE 11 de las excavaciones de La Palomera (San Pedro), nivel correspondiente a un vertedero de la legio VI de época julio-claudia, si bien podríamos concretar aún más la fecha por los materiales que la acompañan en un momento tiberio-neroniano (20-70 d.C.) (Morillo, 1999, 655 y ss., tablas III-VII. Morillo; García, 2006, 256, fig. 62) (fig. 3, 3). Dicha cronología convierte el ejemplar leonés en una de las primeras evidencias del uso de estas loricae en el Imperio, paralelo por tanto a los ejemplares arcaicos atestiguados durante la invasión de Britania. El ejemplar leonés posee un perfil muy sencillo, pues se trata de una simple lámina rectangular cuyo extremo se 
aguza y se enrolla sobre si misma. Gracias a la morfología de este espécimen podemos cuestionar la teoría propugnada por Robinson según la cual los accesorios para lorica fabricados en los inicios de la producción de esta categoría de corazas se caracterizaban por un mejor acabado de las piezas, cuyos contornos contaban con perfiles complejos y simétricos (Robinson, 1975, 180). Los ganchos de este primer periodo, con el que se corresponde el ejemplar de La Palomera, según Robinson deberían poseer láminas con el lado menor próximo al gancho curvado, curvatura que en algunos objetos se prolongaría al perfil de la placa propiamente dicha. El gancho de León demuestra algo que ya quedaba patente desde hace algunos años, el que la teoría de Robinson basada en criterios estilísticos era sumamente cuestionable, pues de forma sincrónica aparece en los campamentos del limes una rica gama de variantes en las que predominan precisamente los ejemplares más sencillos, como no debiera de extrañar ante objetos tan funcionales y frágiles, aspecto este último que implica un constante mantenimiento y reparación de los elementos dañados.

Prácticamente coetáneos, pues se datan en época claudio-neroniana, son los importantes restos de armaduras de la legio VI en León aparecidos en "La Praviana" (c/ General Mola con Plaza del Conde Luna), vinculados a un taller de fundición, dada su asociación con escorias, crisoles, piezas inacabadas y un horno (Aurrecoechea, 2006a, 309-334). Se localizaron más de 20 grupos diferentes de flejes en dos unidades estratigráficas (U.Es 1040 y 1042), ambas correspondientes al momento final del campamento julio-claudio (Morillo; García, 2006, 255, fig. 62), pudiéndose identificar varias láminas de hombreras, tanto superiores como inferiores, un plancha doblada perteneciente a una lámina ventral de la faja, etc. (fig. 3, 4-6 y fig. 8-2 y 3).

También adscritos a los momentos iniciales de utilización de estas armaduras son tres flejes de coraza, en estado muy fragmentario y precaria conservación. Fueron descubiertos en las excavaciones leonesas de la calle Plegarias c/v Ramiro III, concretamente en la UE 1086, zona de cannabae situada justo a la salida de la via praetoria. Dicho nivel pertenece al derrumbe y amortización de las estructuras de adobes que conformaban una ferrería romana de la legio VI, derrumbe fechado entre el año 70 y el momento de llegada de la legio VII, si bien este nivel arqueológico fue alterado parcialmente para disponer unas estructuras edificadas en los primeros momentos de esta última legión (UE 1075 y 1076), por lo que su cronología cae ya en el último cuarto del siglo I d.C. (Aurrecoechea, 2006a, 315. Morillo; García, 2006, 256, fig. 62). Su datación, claramente atribuible al período flavio (70-98 d.C.), convierte estos exiguos fragmentos en otra manifestación temprana de este tipo de corazas en el fuerte de León.
Desde el punto de vista numérico, el grueso de los materiales asociados a esta categoría de armaduras se documentó en la Plaza del Conde Luna, 2, donde apareció representada toda la tipología de elementos en cobre/bronce que engalanaban dichas piezas (bisagras lobuladas, discos repujados, ganchos, etc. Aurrecoechea, 2006a, 309-334, fig. 6-9. Fig. 4, 1-8). El conjunto estaba asociado nuevamente a un taller de fundición, ya que casi todos los especimenes habían sido arrancados de sus placas de hierro originales, lo que provocó el deterioro de los objetos. Esta circunstancia apunta claramente al reciclaje del material por parte de un artesano del metal que estaba preparando su refundición para elaborar nuevos ejemplares. Asimismo se hallaron piezas inacabadas y otros vestigios que confirman la presencia del mencionado taller. También es digno de reseñar el hecho de que este conjunto de accesorios de bronce no forman un lote homogéneo, pues no sólo conviven en el mismo depósito restos de corazas pertenecientes a distintas clases (al menos "Corbridge" y "Newstead"), sino que incluso piezas con la misma función dentro de un mismo tipo de lorica segmentata tienen una decoración diferente, como podemos constatar en los discos repujados.

Los fragmentos de lorigas aparecieron concentrados en dos unidades estratigráficas (UE 107 y 110) que realmente era un único nivel arqueológico. Dicho nivel era la tierra arcillosa de color marrón verdoso con la que se reparó el terraplén original de la legio VII que había sido desmantelado previamente durante el siglo II y la primera mitad de la tercera centuria para construir una serie de hornos. El material cerámico asociado, junto con las monedas que lo acompañaban (antoninianos de Galieno y Claudio II), fechan claramente el contexto arqueológico de las armaduras que tratamos en el último cuarto del siglo III (Aurrecoechea, 2006a, 317-318).

Entre los hallazgos de la Plaza del Conde Luna, 2 encontramos una serie de bisagras lobuladas empleadas para unir las placas del collar y la hombrera superior. Casi ninguna de ellas conserva restos de la lámina de hierro a la que estaban sujetas, por lo que no podemos aventurar el lugar concreto de la armadura donde se alojaron (fig. 4, 2-4). Sólo en un caso podemos asegurar su pertenencia a una placa media del cuello, pues contamos con un escaso pero significativo indicio consistente en un fragmento recto de la placa de hierro con borde engrosado para proteger el cuello del soldado (fig. 4, 1). Los tamaños varían desde ejemplares pequeños a otros más grandes. La forma de los lóbulos también es diferente de unos especimenes a otros, lo que confirma que pertenecieron a diferentes armaduras. Abundan las bisagras bien perfiladas con lóbulos perfectamente definidos, contando incluso con un testimonio de perforación triangular, presunto rasgo de las charnelas "Corbridge" tempranas. Llama la atención la ausencia, en los ejem- 


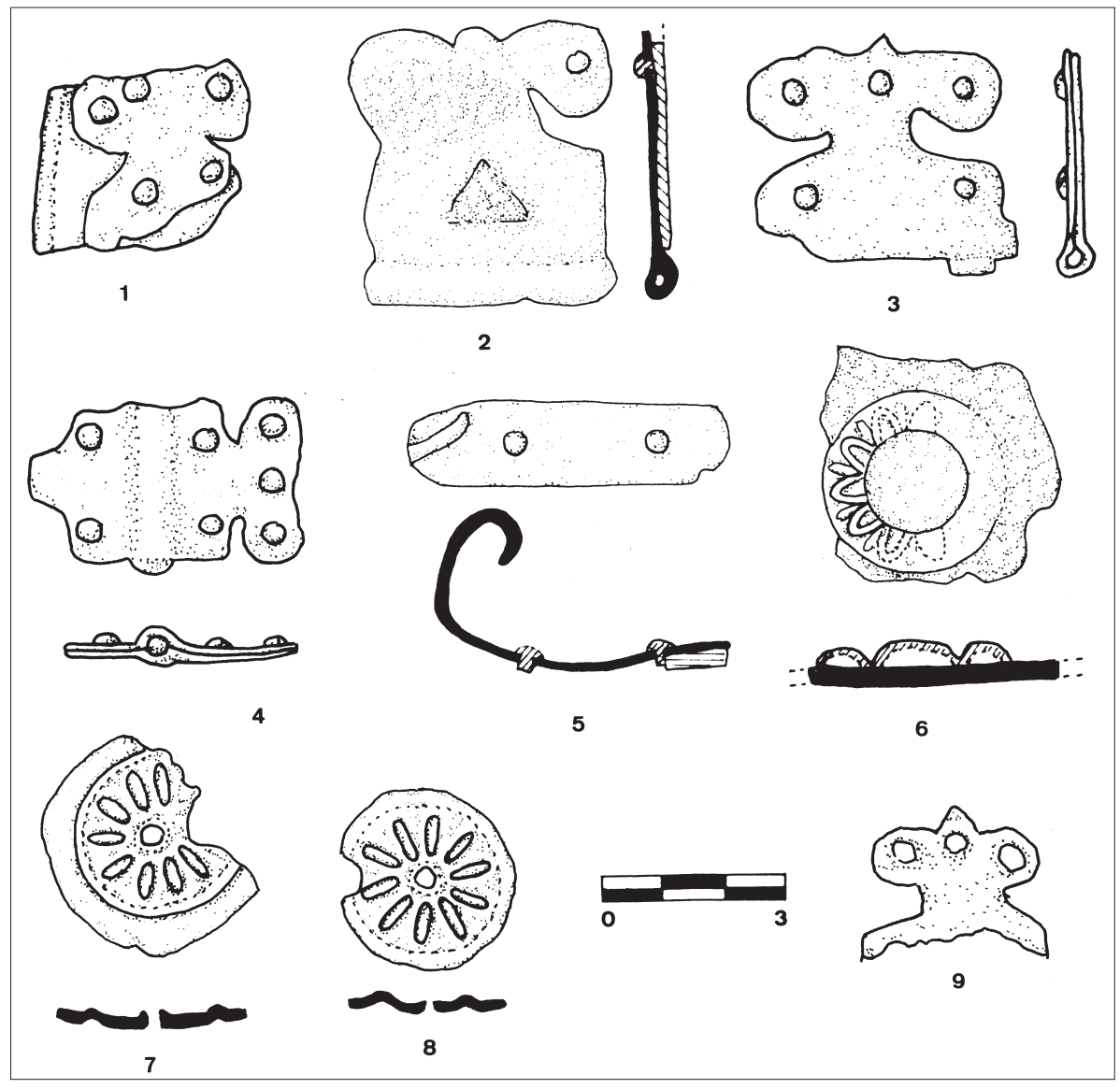

Figura 4. 1 a 8.- Accesorios de armaduras "Corbridge" de la Plaza del Conde Luna (León).

9.- Bisagra "Corbridge" de Calvo Sotelo (Astorga).

plares leoneses, de los típicos círculos troquelados que suelen decorar el contorno de los agujeros donde se insertan los remaches, característica ésta que aparece en muchas de las piezas de la primera centuria. Estas bisagras lobuladas son muy comunes, por lo que podríamos indicar numerosos paralelos, así aquellos de Broxtowe, Londres, Wroxeter (Gran Bretaña. Webster, 1958, fig. 3, 8, fig. 6, 159, fig. 8, 257) o Vindonissa (Suiza. Unz; Deschler, 1997, Taf. 34-35), etc.

Otra evidencia descubierta en la Plaza del Conde Luna, 2 son los discos repujados, uno de los elementos más ornamentales de esta categoría de corazas (fig. $4,6-8)$. Se trata de delgados apliques circulares ubicados por lo general en cada una de las placas de la hombrera superior y en la pechera, en el lugar en que se alojan las correas internas que articulan las placas, sirviendo de cabezas decorativas para los remaches que sujetan dichas correas. Por regla general, todas las piezas constatadas en el Imperio se circunscriben a un repertorio ornamental muy limitado, basado en el esquema radial que proporciona un objeto de forma circular. Todos los ejemplares de León tienen un diseño vegetal a base de pétalos, conforme a una sintaxis decorativa que es la más característica de estos accesorios "Corbridge" y que se encuentra repetida hasta la saciedad en todos los hallazgos de esta clase esparcidos por el orbe romano. No obstante, ninguno de los discos repujados de León que estamos estudiando fue elaborado con la misma matriz empleada para estampar el diseño, dato que nuevamente avala su pertenencia a diferentes loricae segmentatae. Piezas y decoraciones semejantes constatamos en Vindonissa (Unz; Deschler, 1997, Taf. 31) y en otros muchos campamentos romanos.

Otro elemento característico de las armaduras tipo "Corbridge" descubierto en Conde Luna son las placas charneladas para hebillas o correas de cuero (Aurrecoechea, 2006a, 324, fig. 6, 12-14). Al menos tres de estas placas, adscritas al grupo "C.ii" de Thomas, pertenecen a las tiras de cuero que unían en las variantes "Corbrid- 


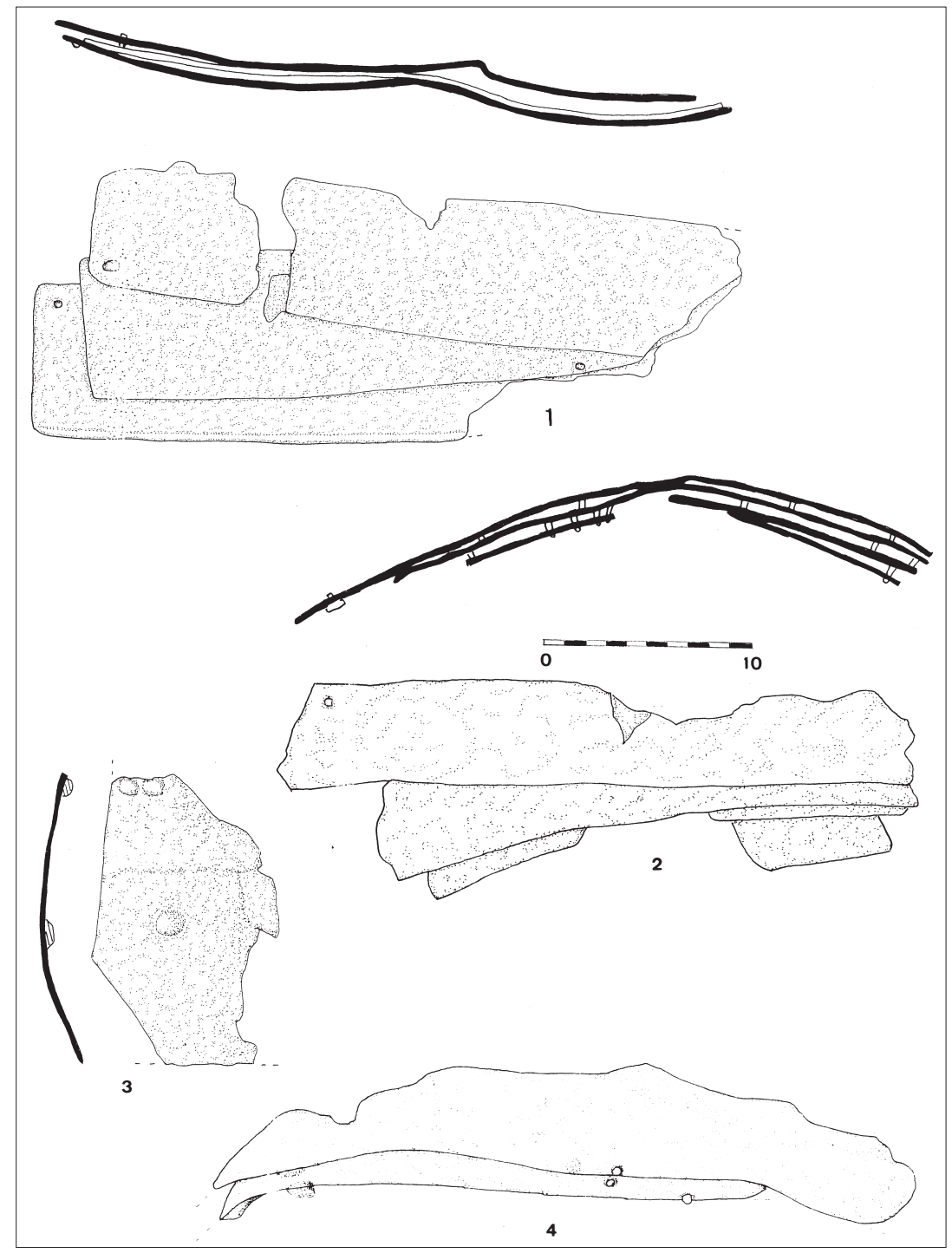

Figura 5. Vestigios "Corbridge” de Puerta Castillo-Santa Marina (León).

ge-A" y "B/C" las pecheras y espalderas superiores del lado izquierdo y derecho entre sí, a través de la placa media del cuello. Aunque también pudieron pertenecer a las tiras que unen las pecheras con el peto en la categoría "Corbridge-A". Los fragmentos son claramente identificables por el par de remaches característicos de estos objetos y las dimensiones que ostentan. Otro fragmento de placa debió pertenecer a una hebilla ubicada en posición similar a la descripción anterior. Los paralelos para nuestros ejemplares son abundantes, como aquellos procedentes de Carnuntum (Robinson, 1975, fig. 179), Hod Hill (Brailsford, 1962, fig. 3, A64), Colchester (Hawkes; Hull, 1947, fig. 102, 14-15), etc.
Los cierres verticales $u$ horizontales mediante ganchos son característicos tanto de las corazas "Corbridge" como de las "Newstead". La función principal en el tipo "Corbridge" fue unir las dos mitades de la faja, mientras que en la categoría "Newstead" se emplearon básicamente para abrochar el collar con el peto. Por tanto, en las primeras armaduras mencionadas era necesario un número mayor de estos ganchos. En el depósito de la Plaza del Conde Luna, donde conviven las dos categorías de armaduras, llama la atención el escaso número de estos objetos hallados, pues sólo hemos constatado un único ejemplar (fig. 4,5 ), perteneciente a la clase "H.i" de la clasificación de Thomas (2003, 91- 
108). Este dato contrasta con la abundancia de ganchos descubiertos en otras excavaciones del mismo yacimiento, hecho este último que está en sintonía con lo que ocurre en la mayoría de los campamentos romanos, donde dichos ganchos son un hallazgo rutinario y habitual. Al ser un descubrimiento tan común desistimos de citar ejemplares semejantes para la pieza de León.

Un nutrido grupo de flejes de lorica segmentata apareció en la UE 4124 del Espacio VII de las excavaciones de Puerta Castillo-Santa Marina (León. Fig. 5, nos. 1, 2 y 4). Las piezas, descubiertas junto a los restos de una manica, parecen haber sido halladas in situ, dado el agrupamiento y la disposición de los diversos restos. Localizadas sobre la superficie de circulación de un edificio interpretado como un almacén en torno a patio, habían sido aplastados por el derrumbe de la techumbre, perteneciendo por tanto al nivel de abandono y colapso de la estructura, el cual se fecha en el tercer cuarto del siglo III. En cuanto a la interpretación de los restos, todos los flejes pertenecen a las láminas ventrales de una faja, constatándose también la placa que descansa sobre la cadera o faldón. Todas las piezas fueron privadas de los elementos de bronce que complementaban las placas, salvo los pequeños remaches internos que sujetaban las correas de cuero, por lo que podemos asegurar que nos encontramos ante una coraza amortizada dispuesta para ser reciclada. Queda por dilucidar la categoría de loriga de la que formó parte, labor que se complica ante la parquedad de los testimonios conservados y la ausencia de los cierres de bronce que abrochaban la faja. Ateniéndonos a la cronología del contexto arqueológico, hacia el 250-275 d.C., podríamos presuponer que nos hallamos ante una lorica segmentata de tipo "Newstead", pues existe una creencia generalizada de que las corazas "Corbridge" ya habían dejado de usarse hacía casi una centuria. No obstante, el campamento de León ha aportado pruebas documentales de la existencia de armaduras segmentadas de tipo "Corbridge" en fechas tan tardías como finales del siglo III. Entre los hallazgos tardíos de corazas "Corbridge" se encuentra el procedente de las excavaciones en la plaza del Conde Luna, 2, siendo éste un descubrimiento que guarda muchas similitudes con el que tratamos, pues en ambos los fragmentos de armaduras constatados estaban siendo sometidos a reciclaje. La diferencia entre uno y otro procede de la categoría de los restos, pues mientras que en Puerta CastilloSanta Marina tenemos el material de hierro inservible, en Conde Luna lo que encontramos son los accesorios de cobre/bronce preparados para su refundición. El descubrimiento de Conde Luna nos hace ser cautos a la hora de catalogar piezas de difícil adscripción morfológica teniendo en cuenta sólo la datación estratigráfica. Para intentar dilucidar definitivamente la clase de armadura encontrada en Puerta Castillo-Santa Marina hemos analizado la anchura del fleje que forma el faldón, observando que sólo mide 5’2 cm, dimensiones similares a las que componen el resto de la faja. Estas dimensiones nos llevan a pensar que nuestros ejemplares pertenecen a una lorica de la categoría "Corbridge", ya que en los especimenes "Newstead" la placa del faldón es más ancha que las láminas ventrales. De este modo, las piezas que exponemos nuevamente constatarían la pervivencia de armaduras "Corbridge" en contextos tan tardíos como la segunda mitad de la tercera centuria.

También provenientes de las excavaciones de Puerta Castillo-Santa Marina son un par de fragmentos de flejes encontrados en la UE 4016 del Espacio III. La génesis del estrato donde fueron descubiertos es la misma que la que originó el hallazgo de los ejemplares de la UE 4124 que comentamos en el párrafo anterior, es decir el colapso del tapial que conformaba la mayor parte del cierre de los muros de la construcción romana y de su techumbre, lo que explicaría la abundancia de material latericio. Su cronología es, por tanto, idéntica a la de sus homólogos, el tercer cuarto del siglo III. Uno de los fragmentos es tan exiguo que no permite interpretación, pero otro de ellos, a pesar de su reducido tamaño, conserva una serie de remaches que nos permiten una clara adscripción tipológica. La disposición de dichos remaches nos indica que nos encontramos ante un fragmento de peto correspondiente a una armadura del tipo "Corbridge-A" (fig. 5, 3). Sólo en los petos de la expresada categoría concurre la circunstancia de poseer un remache para sujetar el disco decorado mediante repujado, aquel que se conserva en el centro de nuestra pieza, debajo de sendos remaches empleados para asir una placa charnelada con hebilla. De este último elemento se conservan dos de los clavos que fijaban una de las chapas del par que suelen componer estos cierres. La aparición de material tan antiguo, como son las corazas "Corbridge-A", en niveles de la tercera centuria, no dejaría de sorprendernos si se tratara de un hecho aislado, pero al contar con otros antecedentes en el mismo yacimiento sólo aporta nuevas pruebas de un fenómeno ya confirmado.

Respecto a las corazas que tratamos, quizá la novedad más remarcable sea el hallazgo de restos "Corbridge" en Astorga, datados en una época tan avanzada como es el tránsito entre el siglo tercero y el cuarto. Nos referimos a una bisagra documentada en la UE 6001 de las excavaciones realizadas en la Plaza de Calvo Sotelo, 10 (fig. 4, 9). Este descubrimiento confirma la pervivencia de los protectores segmentados del tipo "Corbridge" hasta prácticamente los inicios del Tardoimperio. Debemos de tener en cuenta que el ejemplar de Astorga no puede ser interpretado como residual de una época anterior, ya que el yacimiento donde se localizó dejó de ser una base militar bajo el reinado de Tiberio, para transformarse en un núcleo urbano. Con los conocimientos 
actuales, podemos asegurar que las tropas romanas abandonaron Astorga por aquellas fechas y que no volvieron a la ciudad hasta el último tercio del siglo III, como queda confirmado tras el análisis de los restos castrenses aparecidos en este emplazamiento ${ }^{5}$.

Para terminar de completar el panorama referido a estas piezas, sería obligado mencionar los hallazgos localizados en otros enclaves militares españoles, como el de Herrera de Pisuerga, en Palencia, o Petavonium (Zamora), si bien la información que se posee actualmente es muy escasa. De Pisoraca (Herrera de Pisuerga) proceden una serie de ejemplares (bisagras, ganchos, etc.), publicados en varias ocasiones sin alusión al contexto arqueológico en el que fueron descubiertos (García, 1999, 14, fig. 1, 4. Pérez, 1996, fig. 5. Fernández, 1994, fig. 2, 9). También ignoramos el contexto en el que aparecieron los fragmentos encontrados en el asentamiento de la legio X gemina en Rosinos de Vidriales (Petavonium), los cuales se exhiben en el Museo de Zamora, pues aún permanecen inéditos. Actualmente los descubrimientos realizados fuera del área leonesa solo tienen un valor testimonial, ya que desconocemos las circunstancias de su hallazgo.

\section{ARMADURAS DEL TIPO “NEWSTEAD”}

Aunque los primeros testimonios de este tipo de armaduras se documentaron en los trabajos efectuados en el Waffenmagazin del fuerte legionario de Carnuntum durante las postrimerías del siglo XIX, no sería hasta las investigaciones de Robinson cuando se lograran aislar estos restos y redefinirlos como pertenecientes a un nuevo tipo de corazas. Dicha reinterpretación fue posible gracias a la notable mejora en el conocimiento de las lorigas segmentadas romanas que supuso el hallazgo de Corbridge, pues pudo comprobarse cuan diferentes eran las piezas de dicho ocultamiento de las aparecidas en Carnuntum. Hasta ese momento los investigadores habían supuesto que sólo existía un único tipo de lorica segmentata, tesis que fue desmentida por Robinson (1975, 180-181) al comparar sobre todo las pecheras de Corbridge y Carnuntum. El nombre con el que las conocemos deriva de los importantes restos descubiertos en el cuartel general del fuerte de Newstead (Gran Bretaña) por James Curle en 1905, entre los que destacan una pechera y una espaldera superior casi completas (Curle, 1911, 104-139).

La característica principal que fue primeramente señalada para reconocer esta categoría de armaduras, era el

\footnotetext{
5 Dichos vestigios pertenecientes a la tercera centuria son estudiados en profundidad en la tesis doctoral que actualmente elaboramos.
}

modo de unión entre las placas del collar y las que conforman la faja. Donde el tipo "Corbridge" había empleado unas presillas hembras con un lado curvado orientado hacia el vientre del soldado, la clase "Newstead" utilizaba unas presillas más robustas y rígidas con el lado curvo orientada hacía la cabeza del militar. Además el tipo "Newstead" descartaba completamente los cierres basados en correas de cuero unidas mediante hebillas, los cuales aparecían en la categoría "Corbridge" ya únicamente reservados a la unión entre pecheras y espalderas superiores. Las hebillas son sustituidas ahora por sendas perforaciones rectangulares efectuadas en la placa de hierro que están perfiladas por un marco de cobre/bronce. A través de la perforación se hace pasar una presilla tubular, conseguida mediante el simple procedimiento de volver una placa sobre si misma. El conjunto se aseguraba mediante una varilla que era alojada en el hueco cilíndrico del tubo.

Las primeras reconstrucciones que intentaban definir el aspecto de estas loricae fueron víctimas de la escasez de datos con los que se contaba. Tras la propuesta inicial de Curle (1911, 157-158, lám. 22), Robinson establece un esquema que tuvo gran predicamento entre los investigadores del equipo militar, los cuales no se atrevieron a cuestionar hasta tiempos recientes. Para Robinson (1975, fig. 181), las placas del collar y de la hombrera superior no contaban con bisagras, como sus homónimas del tipo "Corbridge", sino que eran remachadas unas sobre otras. Esta particularidad dotaría a los ejemplares "Newstead" de una rigidez paralela a las armaduras posteriores de época medieval. Respecto a los flejes de la faja, estos se abrocharían gracias a unas presillas tubulares por las que se deslizarían una serie de varillas, o por las que se harían pasar sendos lazos de cuerda que ataran unas placas a otras.

Poulter (1988) fue el primero en poner en tela de juicio algunos de los postulados de Robinson, aunque no de un modo muy acertado. Por ejemplo, concibió que las pecheras y espalderas superiores se abrocharían con una hebilla que se introduciría en el intersticio dejado por el marco rectangular que figuraba en uno de los lados. Tal posibilidad ha sido duramente criticada, sobre todo porque no se han descubierto nunca hebillas en los contextos arqueológicos donde han aparecido estas piezas, y porque además no existen huellas de desgaste en las superficies de cobre/bronce de los marcos, las cuales se deberían haber producido debido al roce de la hebilla que descansaría sobre ellos (Bishop, 2002, 56-57).

No ha sido hasta hace unos años, con la proliferación de hallazgos de loricae segmentatae adscritos a esta categoría, algunos de los cuales conservaban las claves para ofrecer una aproximación más definitiva al aspecto de estas piezas, cuando se ha estado en disposición de lograr una reconstrucción más aquilatada. Ésta ha venido de la mano de Bishop, investigador que ha centrado buena parte de su carrera profesional desde la década de 


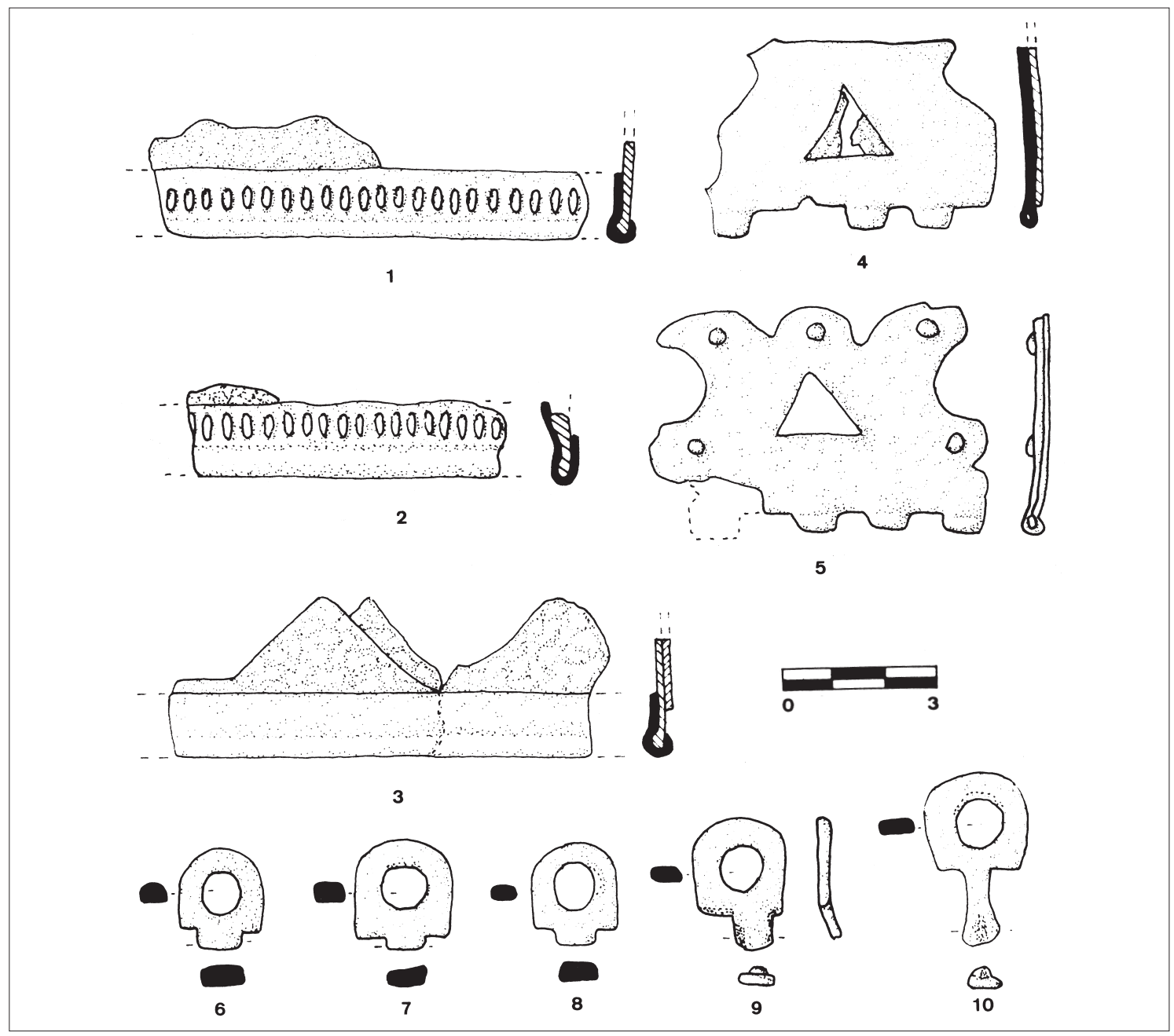

Figura 6. Accesorios de armaduras "Newstead" de la Plaza del Conde Luna (León).

1990 en el estudio de las armaduras segmentadas romanas (fig. 2, 3). Una primera cuestión que llamó la atención de Bishop fue el hallazgo de una espaldera superior en Carlisle (Gran Bretaña) que conservaba una bisagra lobulada de gran tamaño (Caruana, 1993). Bisagras similares habían sido constatadas en el Waffenmagazin de Carnuntum, si bien estas piezas al carecer de paralelos nunca fueron correctamente interpretadas. La solución de Robinson de collar y hombreras formadas por placas rígidas remachadas no estaba basada en ningún testimonio material, pues ninguna de las armaduras tenidas en cuenta por Robinson conservaba la zona donde podría alojarse una bisagra. Con las evidencias actuales sabemos que las armaduras "Newstead" contaban con grandes bisagras exactamente en los mismo puntos que las corazas "Corbridge", es decir, articulando la placa media del cuello con la espaldera y la pechera; así como la hombrera superior central con la delantera y la trasera (Bishop, 1999, 36). Otro punto oscuro era la unión entre pecheras y espalderas superiores, abrochadas mediante presillas tubulares según Robinson, o con hebillas conforme a Poulter. Para Bishop ninguno de los dos métodos son válidos, máxime cuando no hay pruebas que garanticen el uso de ninguno de ellos. Con respecto a la propuesta de Robinson, además, resultaría poco efectivo abrochar una pechera con una varilla que atravesara un único tubo, pues el mero movimiento del soldado durante la batalla podría desalojar de su sitio tan frágil abrochado. Parece más plausible utilizar un método que ya se encuentra constatado en los cierres de las pecheras de las cotas de malla y de escamas, consistente en una anilla fundida de perfil cuadrado con un apéndice en forma de "T", el cual se introduce en la perforación de la placa que está flanqueada por un marco de 
cobre/bronce. Tras ser introducida, este cierre lateral se gira para quedar firmemente asegurado. Tampoco se puede descartar un abrochado similar al presente en los flejes de la faja (Bishop, 2002, 56-57).

Con respecto a los cierres de la faja, el diseño de Robinson $(1975,181)$ fundamentado en presillas tubulares ha sido recientemente desmentido, pues al parecer dicho autor se basó en restos identificados erróneamente como flejes de faja cuando en realidad se trataban de otras partes de la coraza, así como en un caso particular de armadura reparada mediante ese particular método (Bishop, 2002, 57). Desde hacía tiempo se producía en los yacimientos castrenses del limes el reiterado descubrimiento de anillas fundidas con un pequeño apéndice rectangular. Al tratarse de objetos aislados, desvinculados de la pieza original de la que formaban parte, la interpretación correcta de los hallazgos era muy difícil. No sería hasta el trabajo de Webster (1992, 116-119) sobre las piezas de Caerleon (Gran Bretaña) cuando comenzara a vislumbrarse el auténtico cometido de estas pequeñas anillas de cobre/bronce, confirmado posteriormente con el descubrimiento de Stillfried (Austria). En este último yacimiento apareció, hace tan solo unos años, un juego completo de láminas correspondientes a la faja de una armadura de tipo "Newstead". En dicho conjunto se pudo comprobar que el abrochado se realizaba mediante una serie de anillas dispuestas en la mitad izquierda, las cuales se hacían pasar por unos orificios situados en el lado derecho cuya forma era rectangular y estaban enmarcados por placas de bronce remachadas en sus ángulos (Eibner, 2000, 32-34). Dicho sistema de perforaciones con marcos rectangulares ya había sido documentado en las pecheras y espalderas de esta misma categoría de lorica segmentata. Evidentemente este método de cierre necesita de un complemento que atraviese los orificios centrales de las anillas para evitar que éstas se salgan de sus marcos, lo cual podría conseguirse con varillas del tipo de las usadas en espalderas y pecheras, aunque ninguna de ellas ha sido localizada in situ. Tras aclarar el modo en que se abrochaba la faja, comprobamos que la región del abdomen en las corazas del tipo "Newstead" se caracterizaba por una mayor rigidez que en las de la clase "Corbridge", lo que podría haber provocado la constante rotura de las anillas y explicar su proliferación en los contextos arqueológicos militares.

Para finalizar con los accesorios de bronce que portaban estas lorigas, tendremos que hablar del enfundado con tiras de esta aleación de los bordes inferiores y superiores de la faja (Bishop, 2002, 58), rasgo éste que se había constatado ya en la vetusta categoría "Kalkriese-A", aunque en esta última el enfundado se localizaba en las placas que bordeaban el cuello, si bien esta peculiaridad parece haberse perdido en la posterior variante "Corbridge". También es probable que las corazas
"Newstead" se complementaban con discos decorados, al igual que la clase "Corbridge", a tenor de la pieza documentada en el Waffenmagazin de Carnuntum, aunque en este depósito coexisten lorigas de los dos tipos, por lo que no se puede asegurar su pertenencia a uno $\mathrm{u}$ otro (Bishop, 2002, fig. 6.1, 7). No obstante, el hallazgo de una pechera "Newstead" en Zugmantel, que conserva un disco sin decoración repujada, indicaría que posiblemente estas armaduras se ornamentaron con dichos elementos, tal y como ha propuesto en su reconstrucción Bishop (2002, fig. 6.3).

Otro punto importante a tratar es la cronología de esta variante de lorica, sobre todo porque como tendremos ocasión de comprobar posteriormente los hallazgos de León tienen mucho que aportar en este sentido. Un primer aspecto a desvelar es el momento en que estas armaduras segmentadas comenzaron a utilizarse. La temporalidad del depósito de Carnuntum siempre ha suscitado una gran polémica, aunque la connivencia de los tipos "Corbridge" y "Newstead" ha llevado a pensar que su datación se situaría en los momentos finales de uso de la primera categoría y los inicios de la última, proponiéndose el periodo antonino como el más adecuado para esta fase transicional y concretamente los años centrales del siglo II, aunque se carece de un contexto arqueológico que nos permita asegurar dicha hipótesis (Bishop, 1999, 37). Los hallazgos del "Pozo 1" de Newstead se han datado también en época antonina, aunque se han barajado diversas propuestas cronológicas. Para Robinson (1975, 183-184) las piezas documentadas en dicha estructura serían trajaneas, lo que implicaría retroceder la datación inicial de la variante que tratamos hasta los inicios de la segunda centuria; algo con lo que no está de acuerdo Hartley (1972, 4041), quien considera estos testimonios como pertenecientes al reinado de Antonino Pío o Marco Aurelio; si bien Bishop (2002, 60, nota 7) incluso adelanta su cronología hasta las postrimerías de Septimio Severo, es decir, a la década inicial de la tercera centuria. Comprobamos pues que existían serias dudas sobre la época de aparición de estas lorigas, dato que ha empezado a desvelarse con los recientes descubrimientos producidos en el año 2001 en el cuartel general de Carlisle atribuidos con seguridad a la primera mitad del siglo II y en los que conviven nuevamente piezas de las categorías "Corbridge" y "Newstead" (McCarthy, Bishop y Richardson, 2001; Richardson, 2001). De los contextos derivados de las Guerras Marcomanas acaecidas en la mitad del siglo II proceden algunos fragmentos localizados al norte del Danubio, siendo particularmente remarcables los de Iza (Eslovaquia) (Tejral, 1994, 299-300). Asimismo el conjunto de Stillfried está muy probablemente relacionado con el contexto bélico que acabamos de mencionar, pues el yacimiento fue una base avanzada durante las Guerras Marcomanas, considerándose que las loricae segmenta- 


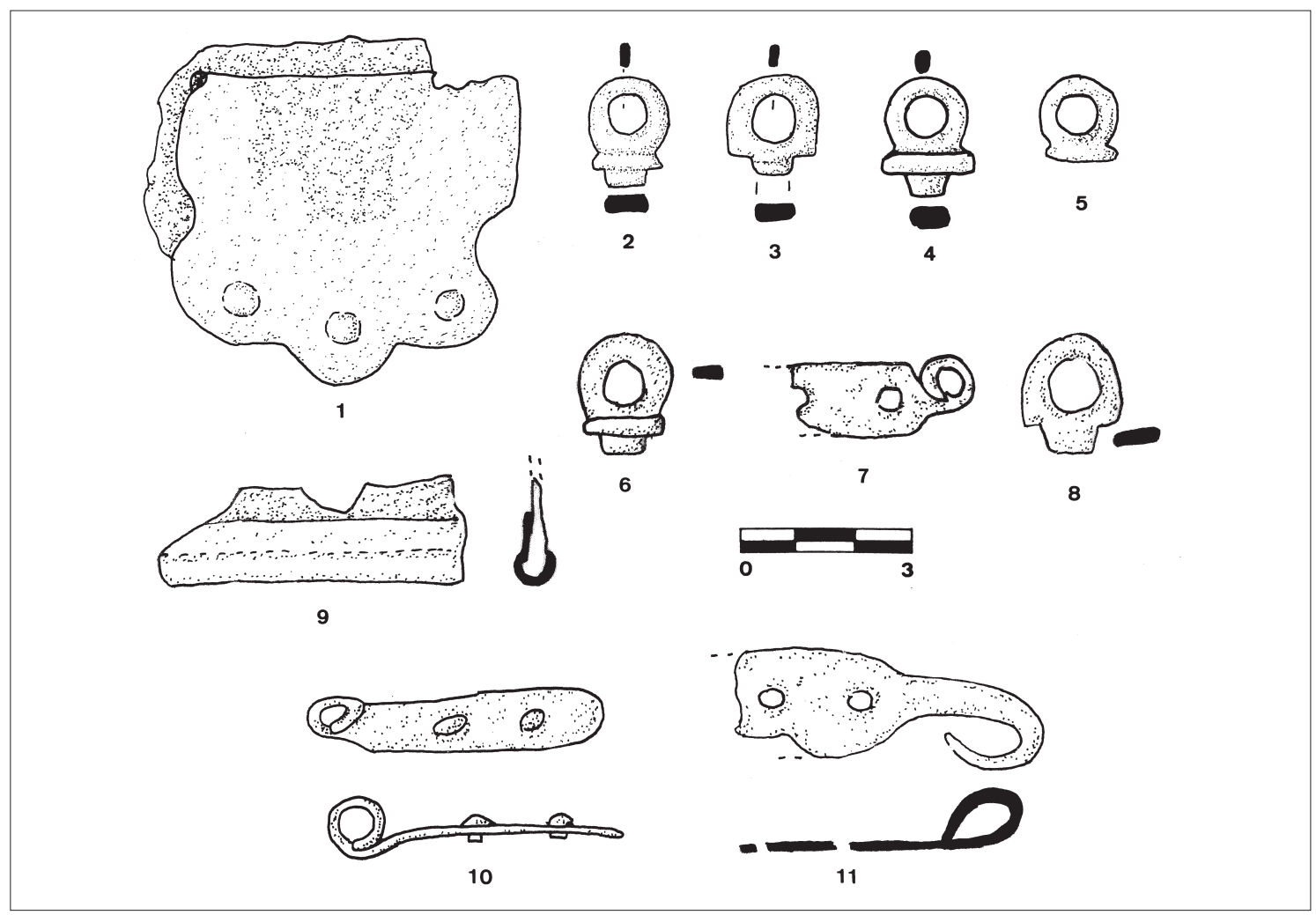

Figura 7. 1 y 3.- Santa Marina con San Albito (León). 2.- Edificio Botines (León). 4 y 5 Puerta Obispo (León). 6 y 7.- Puente Castro. 8.- Lancia. 9.- La Cruz (Astorga). 10.- Calvo Sotelo (Astorga). 11.- Padre Blanco (Astorga).

tae encontradas en ella podrían estar datadas en época de Trajano o Adriano. Ya claramente del siglo III son los restos quemados hallados cerca del praetorium de Zugmantel (Alemania), vinculados con el abandono del sitio en el año 259/260 y los del Weinberg en Eining (Alemania), estos últimos adscritos a un área cultual que nos ofrece un terminus post quem del 229 d.C. (Reinecke, 1927, 161). La cronología más reciente que se ha barajado hasta el presente la proporciona un bisagra encontrada en la Tullie House de Carlisle, fechada en el siglo IV (Caruana, 1993), aunque este hallazgo ha sido considerado como algo residual y por tanto anecdótico (Bishop, 1999, 37). Para Bishop (2002, 49), por tanto, la temporalidad de esta variante de armadura abarcaría desde un momento indeterminado en la primera mitad del siglo II hasta la mitad de la tercera centuria, siendo los fragmentos de Zugmantel fechados en los momentos inmediatamente previos al 260 los últimos testimonios reales de uso.

Centrándonos ya en las armaduras "Newstead" descubiertas en la provincia de León, podemos afirmar que éstas se incorporaron a la impedimenta de los legionarios asentados en el campamento leonés desde sus pri- meros momentos de vida, como confirma el hallazgo de una anilla descubierta en las excavaciones practicadas en el Edificio Botines, ejemplar fechado durante la primera mitad del siglo II (UE 121. Fig. 7, 2). No obstante, el grueso de los materiales leoneses está adscrito al periodo final de uso de estas corazas.

El mayor volumen de hallazgos procede del mencionado taller de fundición localizado en la Plaza del Conde Luna, 2. Entre los bronces inacabados y aquellos preparados para el reciclaje se encuentran bisagras, fundas de faldón, anillas, remaches y otros enseres. Como vimos, el conjunto está datado en las postrimerías de la tercera centuria (Aurrecoechea, 2006a, 317-328).

Las anillas fundidas empleadas para abrochar los flejes ventrales están abundantemente representadas en las excavaciones de la Plaza del Conde Luna, 2 (fig. 6, 6-10). Entre la docena de ejemplares encontrados, dos están claramente inacabados (fig. 6, 9 y 10) y otros cinco dudosamente inacabados. Todos ellos están adscritos al modelo "I.iii" de la clasificación de Thomas (2003, 109-113). En diferentes yacimientos militares están presentes cierres de este tipo sin acabar, En el denominado "grupo 4" del sumidero de las termas de 
Caerleon encontramos una pieza datada entre el 160 y el 230 d.C (Zienkiewicz, 1986, 175, fig. 57, n.30). La fabricación de estos accesorios de armadura no estuvo restringida al interior de los campamentos, como demuestran los hallazgos de anillas inacabadas en asentamientos civiles que viven a la sombra de los enclaves militares. Así, en el vicus próximo al campamento de Mamucium (Manchester, Gran Bretaña) encontramos uno de estos cierres (Bryant et alii, 1986, 67, fig. 5. 5, n. 3150 ); mientras que de las canabae de Caerleon procede otro ejemplar sin rematar (Evans, 2000, 371, fig. 90, n. 130). Entre los ejemplares terminados de León se constatan dos tipos distintos. Algunos presentan un perfil sin interrupción entre la anilla y el vástago, mientras que otros cuentan con un resalte. Los dos tipos son sin duda coetáneos, como demuestra su hallazgo simultáneo en conjuntos como el "grupo 4" de las termas de Caerleon y las canabae del campamento. Aunque Bishop ofreció un listado de hallazgos britanos (Bishop, 1999, 41), nosotros queremos señalar especialmente alguno de ellos. Respecto a la primera categoría podemos señalar varios paralelos. Cuatro ejemplares fueron hallados en Myrtle Cottage Orchard, Caerleon, todos ellos pertenecientes a contextos del siglo III (Fox, 1940, 136, fig. 8, n. 36). En el grupo 4 de los sumideros de los baños de Caerleon, datables en el período 160-230 d.C., encontramos otra anilla (Zienkiewicz, 1986, 175, fig. 57, n. 29), así como en las canabae del mismo asentamiento (Evans, 2000, 373, fig. 90, n.133). De Chester procede otro ítem (Webster, 1953, 8, fig. 5, n. 6). Respecto a la segunda categoría, que coincide con el grupo "I.i" de la tipología de Thomas (2003, 109-113), dos piezas idénticas fueron halladas en Chester (Thompson, 1962, 3, fig. 2, n. 4), así como en Hunter Street (Newstead, 1939, 59, fig. 12, n. 5). Otro paralelo exacto, descubierto en un contexto de finales del siglo IV o principios de la centuria siguiente, es el de Blackfrians Street, Carlisle (Mc Carthy, 1990, 120, 122, fig. 109, n. 48). El "grupo 4" de las termas de Caerleon, (Zienkiewicz, 1986, 175, fig. 57, n. 31) y en las canabae, (Evans, 2000, 373, fig. 90 , n. 134), nuevamente proporcionaron objetos de esta categoría.

Tres bisagras de la clase "Newstead" se identificaron en el depósito que tratamos (fig. 6, 4-5), todas ellas pertenecientes al grupo "F.viii" de la clasificación de Thomas (2003, 62-85). Ejemplares semejantes son los de Carlisle (Caruana, 1993, 15-18, fig. 1), aunque aún guardan más semejanza morfológica los descubiertos en Carnuntum (Von Groller, 1901, 39-45, taf. 29, 57-59) y Great Chesters (Allason-Jones, 1996, 194-195, fig. 12, 50).

En cuanto a las fundas de cobre/bronce situadas en el perfil del faldón para evitar lesiones por roce en la cadera del soldado, dichos protectores eran desconocidos en los estudios sobre armaduras romanas hasta hace poco, si bien recientemente se documentaron piezas similares en Stillfried (Austria) ${ }^{6}$. La coraza austriaca, de la que sólo se ha publicado una breve reseña, fue enterrada ritualmente durante el reinado de Trajano o Adriano (Eibner, 2000, 32-34). Otros ejemplares inéditos proceden de Zeugma (Turquía) ${ }^{7}$. Respecto a los hallazgos leoneses de la Plaza del Conde Luna 2, se constatan piezas sin decoración y otras con ornamentación repujada, lo que demuestra que tenemos documentados los restos de al menos dos armaduras (fig. 6, 1-3).

Continuando con el inventario de lorigas "Newstead" en el fuerte de la legio VII en León, el resto de las excavaciones practicadas confirman la utilización de estas corazas en plena época tardorromana, periodo en el que se pensaba que ya habían dejado de usarse las armaduras segmentadas. De finales del siglo III a principios del IV es una anilla documentada en Puerta Obispo (UE 1097), procedente del nivel de preparación de un callejón tardorromano de cantos y enlosado (fig. 7, 5). En la cuarta centuria se fechan los hallazgos relacionados con un probable vertedero bajoimperial documentado en Santa Marina con San Albito, concretamente nos referimos a una anilla de la UE 4126 (relleno hoyo UE 4125) y una bisagra de la UE 4018 (relleno hoyo UE 4068. Fig. 7, 1 y 3 ). Los recientes trabajos arqueológicos practicados en los Jardines del Cid han aportado otra anilla datada en la cuarta centuria ${ }^{8}$. Pero la cronología más reciente, que cae ya en pleno siglo $\mathrm{V}$, nos la ofrece otro ejemplar de anilla encontrado también en Puerta Obispo (UE 4002. Fig. 7, 4).

Ahora bien, junto a la avanzada cronología que ofrecen las armaduras "Newstead" en el campamento de León, lo más significativo es constatar este tipo de corazas en otros yacimientos próximos de la provincia con similares cronologías. Así, tenemos restos de anillas y ganchos en la habitación sureste del edificio central excavado en Puente Castro (fig. 7, 6-7), mientras que procedentes de Lancia conocemos otros vestigios (Exc. 71/72, E. Isla, $n^{\circ}$ 3488. Fig. 7, 8). Astorga también ha proporcionado diversos elementos de armaduras de esta categoría, todos ellos relacionados con niveles arqueológicos datados entre el último tercio del siglo III y comienzos del IV. Entre otros, podemos citar una funda para faldón de una coraza "Newstead" localizada en la c/ La Cruz 20-24 (UE 1017. Fig. 7, 9); o el gancho descubierto en las termas de Padre Blanco (nivel III, habitación IV), este último vinculado al desmantelamiento de la estancia cuando las termas cayeron en desuso y se convierten en un vertedero intramuros a partir de la segunda mitad de la tercera centuria

\footnotetext{
6 Comunicación personal de M.C. Bishop.

7 Comunicación personal de M. Feugere, quien está estudiando las piezas.

8 Comunicación personal de Fernando Muñoz Villarejo.
} 
(fig. 7, 11). Otra pieza de cronología tardía procede de las excavaciones de la Plaza Calvo Sotelo, 10 (UE 6001. Fig. 7, 10), tratándose de un gancho descubierto en el mismo nivel arqueológico en el que apareció también una bisagra característica de las armaduras "Corbridge", lo que confirma nuevamente la coexistencia y pervivencia de ambas variantes hasta las postrimerías del Imperio.

Igualmente destacable es que, por el momento, apenas conocemos otros vestigios españoles atribuibles a armaduras "Newstead" fuera del área leonesa, a excepción de una probable anilla del campamento de Herrera de Pisuerga, publicada reiteradamente aunque sin referencia a su posición estratigráfica (Fernández, 1994, fig. 2, 6. Fernández, Pérez, Illarregui, 1996, fig. 1, 6). La falta de hallazgos en otras zonas hispanas posiblemente esté relacionada con la temporalidad de estas piezas y la mayor longevidad de los asentamientos legionarios de León relacionados con la legio VII gemina.

\section{ARMADURAS DEL TIPO "ALBA IULIA" Y PECTORALES CON ORNAMENTACIÓN REPUJADA}

Estas corazas son una forma híbrida entre las armaduras segmentadas y las formadas por escamas, hecho que dificulta enormemente la identificación de estas piezas cuando aparecen fragmentadas (fig. 2, 4). El tipo fue propugnado por Bishop, quien reconoce que no existen vestigios arqueológicos en todo el Imperio que hallan sido inequívocamente identificados como pertenecientes a esta categoría, salvo quizá algunos restos de flejes de Zugmantel y Carnuntum (Bishop, 2002, 62-65). Es por ello que hasta el momento debemos conformarnos con las representaciones iconográficas que denotan su aspecto, entre las que descuella la archiconocida escultura de Alba Iulia (Rumania) que le ha dado nombre.

Uno de los rasgos característicos de estas lorigas es la utilización de grandes pectorales con decoración repujada, situados por parejas sobre la abertura del cuello (Bishop, 2002, 63-64). Este sistema, propio de las loricae squamatae ${ }^{9}$, ofrecía una buena solución al problema de introducir la cabeza por una de estas corazas, ya que permitían una abertura lo suficientemente grande para ello, que se cerraba mediante el solapamiento

9 El modo de abrochar la abertura del cuello mediante grandes pectorales se ha considerado siempre característico de la lorica squamata, si bien recientemente se ha señalado también su utilización en la lorica segmentata de la clase "Alba Iulia" (Bishop, 2002, 63) e incluso tenemos constatada su utilización en las cotas de malla, como se desprende del descubrimiento de Bertoldsheim (Alemania. Garbsch, 1984, 239-53). parcial de una placa sobre otra. Existían varios métodos para abrochar las placas, todos ellos similares a los empleados por las contemporáneas loricae segmentatae del tipo "Newstead".

Una cuestión controvertida fue la funcionalidad de estos pectorales y los propietarios que los poseían. En origen, se pensó que estos accesorios metálicos se empleaban en la hipica gymnasia, lo que fomentaba la idea de que estas piezas eran propias de la caballería romana, hipótesis que empezó a cuestionarse ante la significativa ausencia de este tipo de ejemplares en los fructíferos depósitos de material deportivo encontrados en Rapolano (Italia), Straubing (Alemania) y Eining (Alemania). Dicha teoría fue rebatida por Petculescu (1990, 846), tras estudiar los ejemplares de la Dacia, sobre todo los de Buciumi y Potaissa (Rumania), ya que aparecen asociados tanto a establecimientos militares de caballería como de infantería. Igualmente algunas inscripciones presentes en estos objetos, como la descubierta en Pfünz (Alemania. Garbsch, 1978, 75, O-69), demostraban que sus propietarios estaban adscritos al cuerpo de infantería, al mencionar las centurias a las que pertenecían. Además, estos pectorales suelen aparecer en fuertes legionarios (Lauriacum, Carnuntum, Brigetio o Aquincum; entre otros), lo que llevaba a pensar que fueron probablemente usados por la infantería legionaria mejor que por su caballería, pues esta última era mucho menos numerosa. Empezó entonces a considerarse, además, que estos pectorales se utilizarían en la vida cotidiana del soldado, como un elemento funcional más de su impedimenta, y que su uso no debía restringirse al equipamiento de parada o exhibición. El anhelo decorativo que presentan estos pectorales había contribuido a una interpretación errónea, obviándose además que otras piezas militares igualmente utilitarias gozaban de rica decoración; así las vainas de espada con ornamentación troquelada o las faleras equinas con motivos nielados.

Sobre la cronología, estos pectorales aparecen inicialmente en los contextos arqueológicos de la segunda mitad del siglo II d.C., si bien son más característicos de la centuria siguiente (Klumbach, 1962, 188). Un elemento claro de datación lo aportan las piezas dácicas fechadas entre las guerras marcomanas (166-180 d.C.) y mediados del siglo III, pudiendo avanzarse eventualmente esta temporalidad hasta el tercer cuarto de esta última centuria (Petculescu, 1974-75, 86-87).

En Hispania sólo se ha documentado un pectoral del tipo que exponemos, aparecido en el campamento de la legio VII en León (fig. 8, 1). La pieza fue descubierta en un nivel datado en los inicios de la cuarta centuria, correspondiente a las excavaciones de Santa Marina con San Albito (UE 4018), en el mismo contexto arqueológico en el que se hallaron varias placas de una armadura segmentada, lo que posiblemente avale la utilización de este pectoral en un protector del tipo "Alba 


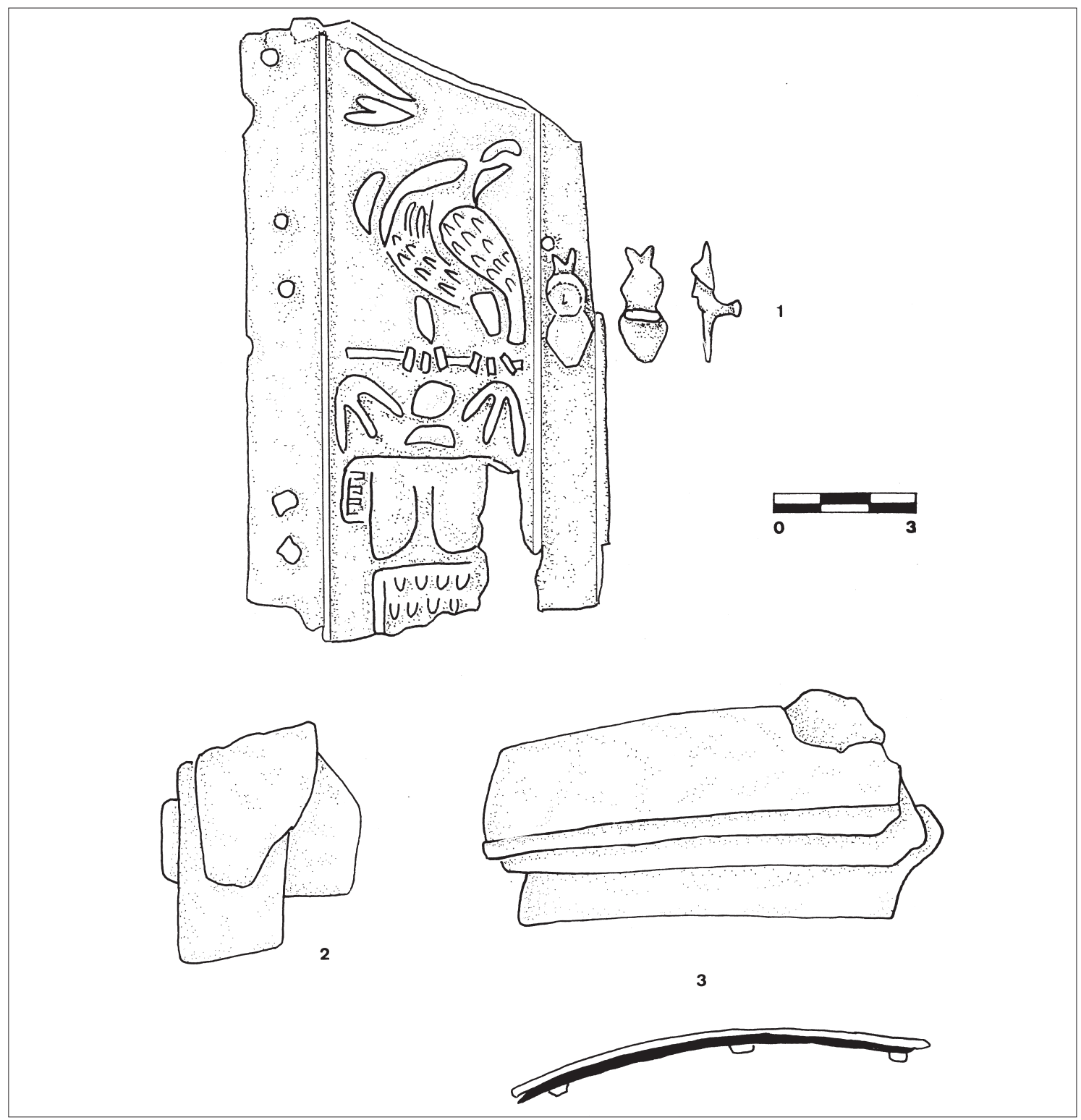

Figura 8. 1.- Pectoral de Santa Marina con San Albito (León). 2 y 3.- Restos de hombreras de La Praviana (León).

Iulia" (Aurrecoechea; García, 2006). Su aparición en una base legionaria apoya su empleo entre las tropas de infantería, confirmando las hipótesis de trabajo que actualmente se imponen en el panorama investigador internacional.

Gracias a su morfología podemos asegurar la disposición del pectoral de León dentro del esquema general de la coraza, posicionado en el lado izquierdo del cuerpo del guerrero, tal y como indica el extremo curvo de la pieza que limitaba con el cuello. El ejemplar que describimos cuenta con una rica decoración repujada en la que se pueden identificar varios motivos (fig. 8, 1). Si analizamos pormenorizadamente la iconografía de la pieza leonesa, comprobaremos que la composición incluye tanto elementos sumamente conocidos, como otros totalmente novedosos. Comenzando por el águila, dicho motivo se repite hasta la saciedad en placas de la misma índole. Por lo general esta ave ocupa siempre el registro superior de los pectorales, es decir, el más cercano al cuello; posiblemente porque la anatomía del animal permitía acoplarlo fácilmente al reducido espacio curvo de dicho registro. Entre los múltiples paralelos 
que podríamos aducir citaremos, a título de ejemplo, los descubiertos en Pfünz (Garbsch, 1978, taf. 9), Zugmantel (Robinson, 1975, 161), Buciumi (Petculescu, 197475, 82-83, fig. 2), Carnuntum (Austria) o FrankfurtHeddernheim (Alemania. Garbsch, 1978, taf. 34-36). El registro inferior del espécimen leonés está ocupado por una especie de trofeo simplificado, en el que se aprecia un casco (visto desde atrás, y no frontalmente o de perfil como suele ser lo habitual) y una armadura; dicha ornamentación no hemos logrado documentarla entre los pectorales publicados. La identificación de este motivo como un trofeo es dudosa, debido tanto a que se aparta de las representaciones convencionales, como a que el casco expuesto parece ser del tipo imperial romano. Dicho casco, aunque representado con rasgos sumamente esquemáticos, presenta un desarrollado cubrenucas y una calota achatada, lo que podría indicar que nos encontramos ante un yelmo de tipo "Weisenau", fechándose éstos últimos en los siglos II y III d.C., cronología coincidente con el pectoral que estamos estudiando. Por lo tanto, podríamos encontrarnos ante la simple plasmación estereotipada de las armas de un soldado romano, como ocurre en multitud de ocasiones sobre otras placas, donde se distribuyen por el campo decorativo, con un auténtico sentido de horror vacui: escudos, estandartes, máscaras, etc. Si bien no encontramos paralelos concretos, para el motivo decorativo que estudiamos, entre los pectorales de armadura o el equipo de parada propio del siglo III, sin embargo podemos localizar representaciones similares entre las estelas funerarias con efigies de soldados datadas en la misma centuria. Así la de Severius Acceptus de la legio VIII Augusta, hallada en Estambul (Turquía. Bishop; Coulston, 1993, 145, fig. 101).

La pieza leonesa ha conservado in situ uno de los pasadores que sujetaban la chapa a la coraza, estando ornamentado dicho pasador con un busto masculino (¿Marte?). El hallazgo de un pasador figurado de este tipo asociado a esta clase de pectorales es de vital importancia, ya que hasta el presente nunca se había constatado tal vinculación. La importancia del hallazgo de León radica no sólo en ser la primera vez que aparecen juntos estos dos elementos, placa y pasador, sino en la constatación de un nueva clase de abrochado de las placas no observada aún. La teoría más difundida señalaba que las chapas eran trabadas mediante presillas que tenían un pie en forma de "T" y una cabeza perforada por la que se deslizaría una barra, tal y como indica Robinson (1975, 161, n 170). Junto al método descrito, otra posibilidad esgrimida era la inserción en los orificios de las placas de pequeños cilindros huecos por los que se haría pasar nuevamente una barra. Esta última hipótesis se sustenta en la aparición de una piezas en Dura-Europos (Siria) con los cilindros descritos (James, $2004,120, n^{\circ} 418$ ). Ahora sabemos que, al menos, exis- tía un tercer método para unir estos pectorales, consistente en un simple pasador en forma de " $\mathrm{T}$ " cuya cabeza estaba decorada con la efigie de una divinidad, lo que no permitía insertar una barra que uniera una presilla con otra. Sería suficiente girar 90 grados el pasador para que el apéndice en " $\mathrm{T}$ " uniera firmemente una chapa con otra. Presillas con bustos figurados similares al de León encontramos en Nijmegen (Holanda. ZadoksJosephus Jitta et al., 1973, 75, nos. 127-28), Carnuntum (Fleischer, 1967, taf. 30, nos. 47, 48, 55-56) o Caerleon (Webster, 1992, 106), si bien jamás habían sido interpretados como accesorios de armaduras.

El pectoral hispano documentado en León también aporta novedades respecto a la datación de estas piezas, pues adelanta su momento final de uso hasta los albores del siglo IV. Esta fecha no debe extrañarnos, por cuanto se conocían ya algunos pasadores con cabeza de "Marte" en contextos de la primera mitad de la cuarta centuria, como el descubierto en Caerleon, si bien nunca se había propuesto una fecha tan avanzada para estos pectorales debido a que aún no se había señalado la relación entre las presillas con bustos y las piezas que tratamos.

\section{PROTECTORES SEGMENTADOS PARA EL BRAZO (MANICAE)}

A lo largo de la historia militar romana, la protección de las extremidades que quedaban expuestas al enemigo durante el combate fue una constante preocupación, sobre todo porque cualquier daño infligido en ellas mermaba la capacidad ofensiva del soldado. Entre ellas, el brazo fue objeto de una especial atención mediante el diseño de un tipo de protector formado por láminas metálicas, denominado manica, que envolvía aproximadamente la mitad del diámetro de la mencionada extremidad. Dichas láminas se sujetaban mediante remaches a un soporte de materia orgánica (cuero, lino, etc.) que estaría en contacto con la piel. Existe un consenso casi generalizado sobre el empleo individual de estas piezas, que cubrirían uno sólo de los brazos del combatiente, aquel en que empuñaba la espada, ya que el otro quedaba resguardado por el escudo, estando aún por dilucidar como garantizaba la libertad de movimiento necesaria. Entre las pruebas a favor del uso individual de estas manicae encontramos la evidencia arqueológica, ya que en los hallazgos aparece siempre un único ejemplar; así como las representaciones iconográficas, donde se plasma siempre un solo protector.

Los primeros testimonios sobre el uso de la manica los encontramos en el mundo griego, siendo mencionada en la literatura militar con el nombre de cheira (Jenofonte XII,5) y existiendo constancia arqueológica de su presencia en el arsenal helenístico de Ai Khanum (Afganistán), datado hacia el 150 a.C. (Bishop, 2002, 18). Ya en el 


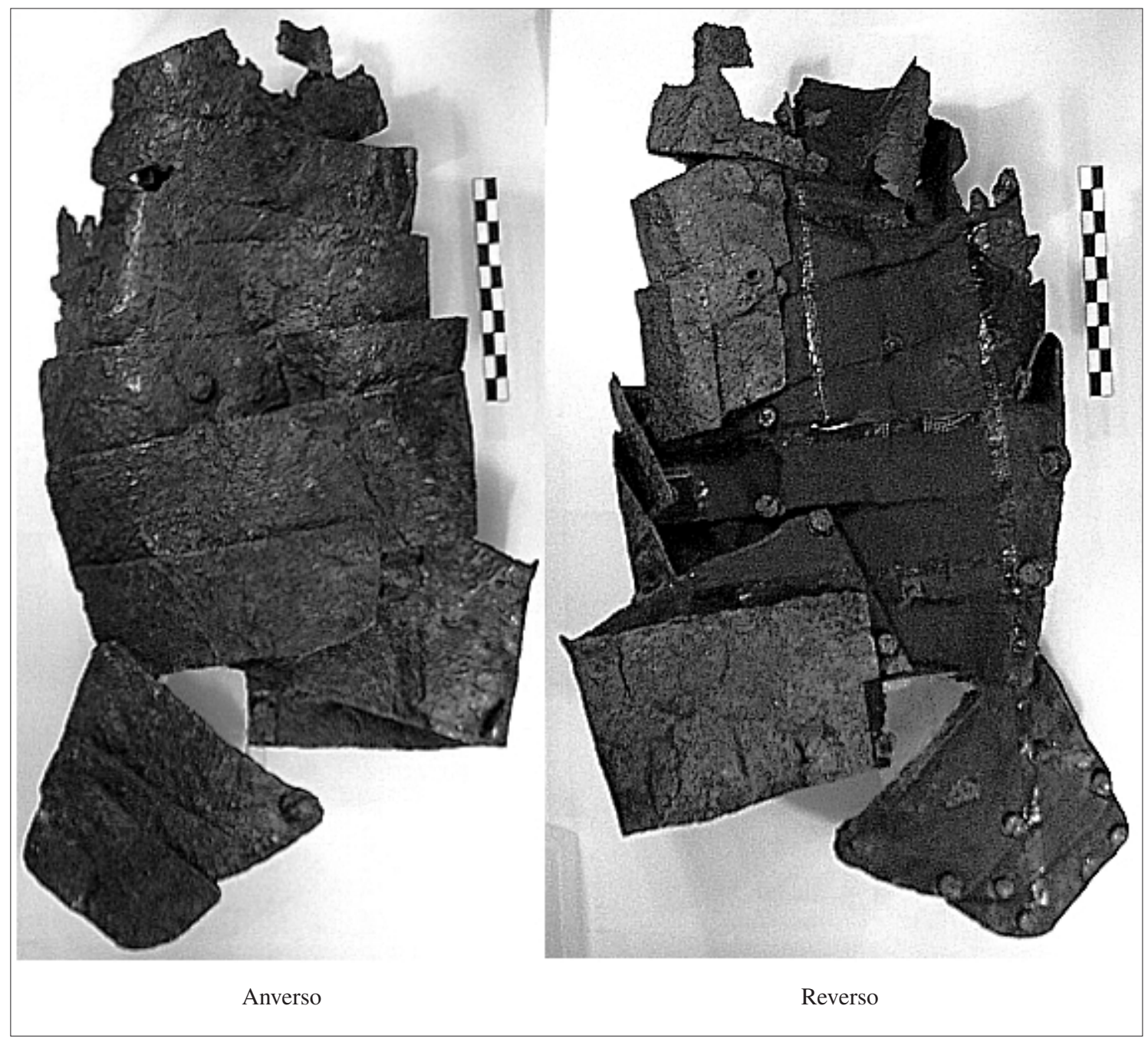

Figura 9. Protector para brazo de Puerta Castillo-Santa Marina (León).

mundo romano encontramos pruebas de su uso en monumentos funerarios erigidos a soldados, como los levantados a mediados del siglo I d.C. en Maguncia (Alemania) a Sextivs Valerius Severus y G.Annivs Salvtvs (Bishop, 2002, 68). De la segunda centuria es el Trofeo de Adamklissi, en cuyas metopas ( ${ }^{\text {os }}$ XVII, XVIII, XX, XXV, etc.) podemos ver a una serie de combatientes con manica en el brazo derecho protegiéndoles hasta la muñeca. Pertenecientes al siglo III son el relieve de Alba Iulia (Bishop, 2002, 62-65) y un grabado de un catafracto descubierto en Dura-Europos (James, 2004, 42-46), estando los brazos y piernas de este último caballero recubiertos por láminas). Finalmente algunas de las imágenes que ilustran la Notitia Dignitatum han sido interpretadas como la última representación conocida en el mundo romano de estos protectores.
Hasta el momento, han aparecido escasas pruebas arqueológicas de estos objetos, lo que resalta la importancia de hallazgos nuevos, como el documentado en León (fig. 9), máxime si tenemos en cuenta que el ejemplar que presentamos se encuentra completo. Descubierto en las excavaciones de Puerta Castillo-Santa Marina, junto a un grupo de flejes de lorica segmentata, apareció en la parte central de una de las estancias (Espacio VII), sobre el suelo de arcilla batida que conformaba el nivel de circulación de la misma (U.E. 4124). El agrupamiento y disposición de las láminas indican que la manica se halló in situ, tal y como había sido abandonada, ya que estaba cubierta por el estrato formado a partir del colapso de las paredes y techumbre de la construcción, derrumbe datado durante el tercer cuarto del siglo III. 
Entre los contados paralelos que podemos aducir citaremos el protector para brazo fabricado en latón de (Gran Bretaña) Newstead (Rusell Robinson, 1975, 184-186); o los ejemplares elaborados en hierro de Carnuntum, Corbridge, Richboroug (Gran Bretaña) y Eining (Alemania) (Bishop, 2002, 68-71). En los últimos años se ha producido un hallazgo muy prometedor en Carlisle que está a la espera de su publicación definitiva. Nos referimos a la localización de dos grandes grupos de láminas, fechadas a mediados del siglo II d.C. (McCarthy, Bishop y Richardson, 2001. Richardson, 2001).

Respecto a la pieza de León, quizá una de las principales novedades que aporta es el remate mediante una serie de láminas trapezoidales de tamaño decreciente, extremo que protegió el dorso de la mano. Extremos semejantes se encuentran testimoniados en las estelas de Maguncia anteriormente mencionadas, si bien hasta ahora no conocíamos ningún testimonio claramente atribuible a esta parte del protector, salvo quizá las dos escamas remachadas procedentes de Eining (Alemania) (Bishop, 2002, fig. 8.4).

\section{TALLERES RELACIONADOS CON LA FABRI- CACIÓN Y EL RECICLAJE DE ARMADURAS SEGMENTADAS}

Aunque en Hispania se han prodigado los hallazgos de diversas industrias relacionadas con el ámbito militar, bien sea cerámicas, latericias u óseas, aún son muy escasas las evidencias de talleres abocados a la elaboración de equipo militar. En este contexto, los diversos descubrimientos acaecidos en excavaciones recientes de la ciudad de León, cobran una especial dimensión, pues estos se han convertido en los primeros testimonios fehacientes de la existencia de esta clase de talleres en los fuertes estables de Hispania.

Desde la publicación de la monografía de Oldenstein (1976, 49 y ss.) se generalizó la idea de que la producción de enseres militares era muy dispersa, pues muchos de los fuertes romanos de los siglos II y III contaban con talleres para la fabricación de los útiles que necesitaban. Los testimonios de fabricae militares, bien en los propios fuertes o en las cercanas áreas civiles, se han prodigado desde entonces, si bien nuestro conocimiento sobre este fenómeno sigue siendo parcial, ya que la mayoría de los hallazgos se concentran en la zona occidental y están circunscritos a las centurias centrales del Imperio.

Hasta el momento se han logrado localizar varios indicios de estas industrias en lugares bastante próximos del campamento de León, aunque separados cronológicamente (Aurrecoechea, 2006, fig. 1 y fig. 10). En concreto conocemos tres talleres, existiendo en todos ellos indicios de la manipulación de lorica segmentatae, bien para su fabricación o su reciclaje. Dos de las manufac- turas están vinculadas con la primera unidad que ocupó el campamento, la legio VI, estando uno especializado en el trabajo del bronce y otro en la forja (Aurrecoechea, 2006a, 3009-334). De la legio VII conocemos un taller claramente especializado en la elaboración de armaduras segmentadas.

La manufactura de la legio VI relacionada con el trabajo del bronce, entendiéndose éste en un sentido amplio como cualquier aleación con base cobre, se documentó en las excavaciones de la "Praviana" (c/ General Mola c/v Plaza del Conde Luna) (Aurrecoechea, 2006a, 315). En ellas se localizaron varias estructuras que abarcan desde los comienzos de la ocupación romana de León hasta el siglo III. Los niveles más antiguos datan de comienzos de la primera centuria, destacando un hogar (UE 1045) elaborado mediante dos ladrillos bipedales colocados sobre su cara ancha, trabados con una fina capa de arcilla de tonalidad roja, fruto de la acción del fuego. Conservaba sobre él un pequeño horizonte de cenizas de tonalidad blanquecina, producto del fuego practicado sobre el mismo. Asociado a las estructuras donde se localizó el hogar se encontraba un nivel de gravas que deparó el hallazgo de terra sigillata itálica y monedas de los reinados de Augusto y Tiberio (Aurrecoechea, 2006a, 316). Si bien en este horizonte no se documentaron bienes muebles que sugirieran una actividad artesanal, los estratos superiores pertenecientes a la época claudio-neroniana ofrecieron una serie de materiales que confirman tal interpretación. Un nuevo hogar fue localizado en la unidad estratigráfica 1040 cuya construcción difiere del anterior, pues estaba compuesto por un aparejo de nódulos de arcilla recocida y fragmentos de cerámicas y teja. Restos de escoria y un posible crisol fueron descubiertos asociados a este horno, así como terra sigillata sudgálica y producciones precoces de sigillata hispánica, que fechan el conjunto en los años centrales del siglo I. Contemporánea es la capa de echadizo (UE 1042) en la que se documenta sigillata sudgálica, lucernas de volutas, numismática datada entre el 50-60 d.C., una numerosa serie de fragmentos pertenecientes a loricae segmentatae, un probable crisol, así como una serie de restos de fundición (la cabeza de un canal de vertido, un fragmento de objeto inacabado, etc.) (Aurrecoechea, 2006a, 317). Aunque no podemos relacionar con certeza la vinculación de esta industria con la fabricación de los accesorios de bronce que complementaban las armaduras segmentadas, la presencia de importantes vestigios de estas corazas en los niveles arqueológicos correspondientes al taller nos inducen a pensar que, al menos, en aquel lugar se manipularon loricae segmentate destinadas al reciclaje.

Las mismas dudas podemos aducir respecto al taller de forja aparecido en la calle Plegarias c/v Ramiro III, pues no tenemos base científica para asegurar que los exiguos restos de flejes de hierro pertenecientes a estas armaduras que aparecieron en la excavación, fueron fabricados o estaban en proceso de fabricación por el 
artesanado que trabajaba en aquella ferrería. No obstante, el sentido común sugiere que la aparición de corazas segmentadas en un sitio como el descrito sólo puede justificarse por su elaboración en aquel lugar (Aurrecoechea, 2006a, 316-317).

Un caso completamente distinto son los sondeos adosados a la muralla tardorromana situados en la Plaza del Conde Luna 2, pues el taller de la legio VII localizado ha dado muestras irrefutables de la fabricación de accesorios para loricae segmentatae in situ (Aurrecoechea, 2006a, 317-328). En las excavaciones pudo documentarse una completa secuencia de la ocupación romana en León, siendo particularmente interesantes para nuestro estudio los niveles correspondientes al siglo III. Se ha comprobado cómo la zona sufre una remodelación en el siglo II y la primera mitad del III, destruyéndose parcialmente el terraplén defensivo de la fortificación, con el fin de convertirse en un área industrial en la que se construye una habitación con suelo de opus signinum y varios hornos. Algo más adelante, en el último cuarto del siglo III vuelve a replantearse la configuración y uso de las instalaciones, desmantelándose los hornos para reconstruir nuevamente el terraplén y erigir un cuerpo interior que se adosa a la torre del recinto amurallado de la legio VII. Adscritos a esta última remodelación, la excavación proporcionó un nutrido grupo de enseres militares entre los que destacan un buen número de fragmentos de armaduras segmentadas. Los restos de corazas aparecieron concentrados en dos unidades estratigráficas (UE 107 y 110), que realmente conformaban un único nivel arqueológico. Dicho nivel estaba constituido por la tierra arcillosa de color marrón verdoso con la que se reconstruyó el terraplén original a finales de la tercera centuria. El material arqueológico asociado consistía en terra sigillata hispánica de transición, cerámicas engobadas y numerario de Galieno y Claudio II, conjunto que fecha claramente el estrato durante el último cuarto del siglo III. A este mismo momento apuntan los hallazgos de la unidad estratigráfica 108, pertenecientes a la fase de arrasamiento de la bóveda de uno de los hornos, donde también se hallaron vestigios materiales del taller que nos ocupa.

En el horizonte arqueológico arriba mencionado se descubrieron hasta 91 accesorios de cobre/bronce, casi todos correspondientes a armaduras segmentadas. Tomado en su conjunto, el material presenta una extraordinaria variedad tipológica, pues es de destacar que incluso las piezas con idéntica función no formaban un lote homogéneo, ya que se documentan accesorios pertenecientes a loricae segmentatae de varias categorías, como son los tipos "Corbridge" y "Newstead". Además piezas adscritas a la misma clase de armaduras contaban con una decoración diferente. También llama la atención la casi total ausencia de láminas de hierro correspondientes a estas armaduras, pues sólo se localizó un pequeño fragmento suelto perteneciente a la lámina final que apoya sobre la cadera. Entre la variedad de objetos podemos distinguir varios apartados. Los accesorios de bronce para armaduras configuraban la práctica totalidad del hallazgo. Casi todos ellos habían sido arrancados de sus placas originales, por lo que algunos están deformados. A menudo incluso quedaban pequeños vestigios de las placas a las que estuvieron adheridos, pudiéndose constatar en el caso de las laminas del faldón como éstas habían sido cortadas en zig-zag, tal y como hubiera hecho un artesano del metal que quisiera trocear unas piezas de por si gruesas y grandes en otras más pequeñas para facilitar su trabajo de desmontaje. Junto a estos especímenes, sin duda utilizados por los soldados, encontramos otros ejemplares que nunca habían llegado a usarse, entre ellos el grupo de los pequeños remaches que servían para unir las tiras de cuero que articulaban los distintos flejes de la armadura. La fragilidad de estos elementos no permitiría su reciclado, al menos en el estado actual de preservación de nuestros ejemplares, los cuales se conservan intactos, incluidas sus delgadas cabezas. Nos encontraríamos pues ante piezas acabadas listas para ser empleadas. También contamos con una pequeña muestra de objetos inacabados, principalmente anillas fundidas que todavía presentan rebabas de fundición y a las que no se les había terminado de eliminar el canal de vertido. Y para terminar, existe un grupo de objetos sin forma, desechos de producción, que contienen rebabas de fundición. Del análisis de los restos materiales se desprende que nos encontramos ante un depósito de piezas en el que conviven elementos destinados al reciclaje, que habían sido desmantelados de varias armaduras distintas, junto con ejemplares en proceso de fabricación y desechos de fundición.

Los paralelos más cercanos para el taller de la Plaza del Conde Luna los encontramos en Augusta Raurica (Suiza) y Carlisle (Gran Bretaña). En la insula 22 de Augusta Raurica se localizaron 40 fragmentos de armaduras segmentadas, junto a restos de piezas en bronce pertenecientes al mismo tipo de corazas descubiertas en un hoyo donde habían sido depositadas por un herrero para su reciclaje (Deschler-Erb, 1999, 85-86, Abb. 99100). Dicha industria se encontró en un área civil y está datado en la primera centuria. En Carlisle se han localizado recientemente una serie de talleres situados al sur de la via principalis, ubicación que coincide con la del yacimiento de León. En ellos se documentan abundantes restos de armaduras segmentadas, protectores de brazos, etc., estando datado el conjunto entre los reinados de Trajano y Adriano (McCarthy, Bishop, Richardson, 2001, 507-508). Otros talleres en los que se evidencia la fabricación de accesorios para lorica segmentata se han localizado en Magdalensberg (Austria) (Deimel, 1987, Taf. 76, 17-28), Vindonissa (Unz ; Deschler, 1997, n. 2334-2335), o en la fabrica de "Gornji trg 3" en Ljubljana (Eslovenia. Vicic, 1999, 15, Abb. 2, 1-6). 


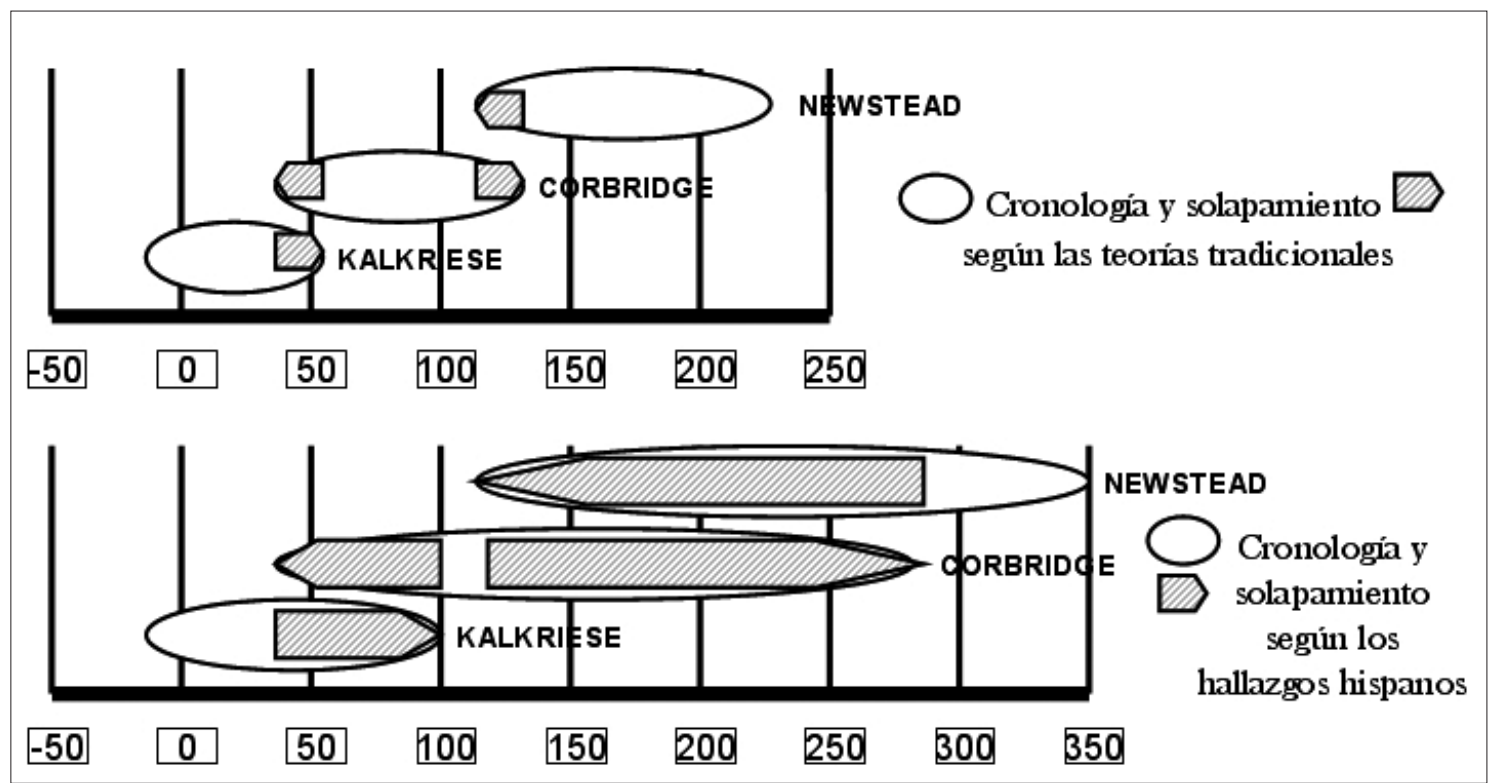

Figura 10. Líneas temporales en las que se compara los datos aportados por los hallazgos hispanos, con la cronología y el periodo de solapamiento que tradicionalmente se asigna a las distintas variantes.

\section{SOBRE LA CRONOLOGÍA Y LA EVOLUCIÓN DE LAS ARMADURAS SEGMENTADAS}

El estudio de las loricae segmentatae descubiertas en la provincia de León pone en tela de juicio la datación que tradicionalmente se asigna a las distintas variantes de estas corazas, manifestando que debe revisarse la cronología final dada a las distintas variantes. El tipo "Kalkriese" parece prolongarse hasta la segunda mitad del siglo I, si bien este dato se infiere del ejemplar aparecido en Iruña y debe ser tomado con cautela, pues sólo poseemos el mencionado indicio y podemos estar ante un fenómeno aislado. Sin embargo, los numerosos testimonios del tipo "Corbridge" vinculados con los yacimientos leoneses, nos permiten afirmar que éste perduró en Hispania, por lo menos, hasta el último cuarto del siglo III. Dicha perduración, además, no debe considerarse residual, dada la abundancia de hallazgos datados en la tercera centuria y su localización en diversos yacimientos de León y Astorga. En cuanto al tipo "Newstead", podemos asegurar que en Hispania aún estaba plenamente vigente durante la primera mitad del siglo IV, y que posiblemente prolongó su uso algunas décadas más. En este caso tampoco podemos interpretar los numerosos descubrimientos de armaduras "Newstead" en el campamento de la legio VII en León como residuales, ya que se constatan en varios contextos arqueológicos de cronología tardorromana del mismo yacimiento. Además, las corazas "Newstead" se difunden en los asentamientos cercanos a dicho enclave durante la etapa bajoimperial, como demuestran los diversos ejemplares de Puente Castro, Lancia y Astorga. Hemos de tener también en cuenta, que estos tres últimos lugares no contaron con fuerzas armadas durante la segunda centuria e inicios del siglo III, periodo de utilización tradicional de esta categoría de loricae según las investigaciones al uso. En dichos asentamientos, la presencia militar se atestigua a partir de la segunda mitad de la tercera centuria y, sobre todo, en el tránsito entre ese siglo y el siguiente. Fue en esos momentos cuando los legionarios de la VII gemina debieron participar en la modernización del sistema defensivo de la zona, como por ejemplo, con la construcción de encintados amurallados, así el de Astorga. Es muy probable que el desplazamiento de efectivos castrenses de la legio VII a estas localidades justifique la aparición de las armaduras que tratamos.

Como hemos comprobado, los yacimientos de la provincia de León ofrecen la datación más avanzada de todas las conocidas en el Imperio Romano (fig. 10). Quedaría ahora por dilucidar si estas cronologías son solo características de Hispania o si pueden generalizarse al resto del Imperio. Somos conscientes de que nuestra provincia presenta una personalidad propia, inherente a las unidades militares asentadas en territorios pacificados, en las que las modas y el equipo perduran mucho más tiempo. Ahora bien, no podemos utilizar dicho argumento en el caso que nos ocupa, pues el horizonte de serenidad que hemos descrito se rompe de forma abrupta durante la segunda mitad del 
siglo III, precisamente durante el periodo que más abundan las loricae segmentatae en la zona. Gracias a las tipologías del equipo militar descubierto, podemos confirmar el reemplazo de las tropas en el fuerte de León, donde se incorporan nuevos soldados llegados de fuera de Hispania. En contraste con la ausencia en la provincia hispana de objetos castrenses de la segunda centuria con paralelos en los campamentos del limes, los materiales del siglo III denotan una fuerte influencia de las tropas establecidas en el Rin, Danubio o las fronteras britanas. Este drástico cambio, que coincide con la expansión de las armaduras segmentadas en nuestro territorio, pudo estar conectado con el establecimiento del Imperio Gálico, o la primera invasión de Hispania hacia el 260 (Aurrecoechea, 2006b, 167-180). Si bien no podemos concretar las causas históricas que suscitaron dicho cambio, lo cierto es que desde entonces se rompe el panorama monótono que caracterizaba la vida castrense en nuestra zona de estudio, renovándose el interés por reforzar el sistema defensivo que protegía el territorio.

Estas circunstancias nos llevan a pensar que las cronologías atestiguadas en Hispania deberán ser tenidas en cuenta a la hora de fechar estas armaduras en el futuro. A la luz de la nueva información proporcionada por las piezas hispanas, creemos razonable generalizar la vida de las corazas segmentadas hasta el siglo IV, desechando las teorías tradicionales que no prolongaban el período de uso de las loricae segmentatae durante el Bajoimperio. Respecto a que las armaduras segmentadas pudieron haber seguido utilizándose en época tardía ya contábamos con algunos indicios que apuntaban en ese sentido, como muy bien señaló Bishop al referirse a las lorigas ilustradas en la Notitia Dignitatum, puesto que entre ellas se constata el tipo segmentado (Bishop, 2002, 91). A este argumento se pueden añadir otros de índole arqueológica, ya que las cronologías tardorromanas no solo están documentadas en Hispania, pues en Britania también se documentan materiales fechados en el Tardoimperio, si bien estos últimos habían sido siempre interpretados como anecdóticos y por tanto desestimados como significativos. Algunos de los hallazgos britanos merecen especial atención. Entre ellos, el protector segmentado para brazo encontrado en Bowes Moor y fechado en la cuarta centuria, por tratarse de la manica más tardía de las conocidas (Bishop, 2002, 91). Especial consideración merece una espaldera de la categoría "Newstead" descubierta en la Tullie House de Carlisle, datada también el siglo IV y considerada como residual en las numerosas publicaciones que se han hecho eco de la pieza (Caruana, 1993. Bishop, 1999, 37). Tal consideración sorprende si seguimos repasando los hallazgos britanos, pues no supone un caso aislado, sino un testimonio más dentro de una nutrida nómina de descubrimientos. Caerleon es un yacimiento que ha pro- porcionado un buen repertorio de materiales aparecidos en contextos tardíos. Cabe citar la serie de ganchos y anillas documentada en varios recintos (baños en el interior del fuerte y puertas del mismo), fechada a finales del siglo III y primera mitad de la cuarta centuria (Zienkiewicz, 1986, 256. Thomas, 2003, 90, Gv, n. 4. Webster, 1992, n. 48, 53 y 54). Algo más avanzadas, ya de la segunda mitad del siglo IV, son un par de anillas de las empleadas para abrochar armaduras "Newstead" encontradas en las excavaciones de la denominada "Puerta Romana" de Caerleon (Webster, 1992, n. 65 and 67). Otros testimonios bajoimperiales proceden de Gales, como por ejemplo, un par de hebillas aparecidas en Loughor y fechadas entre fines de la tercera centuria y la primera mitad del siglo IV (Lloyd-Morgan, 1997, n. 116). Incluso contamos con algunas evidencias cuya cronología cae en el siglo $\mathrm{V}$ avanzado, como las piezas documentadas en la Old Market Street de Usk (Marvell. 1996, 108) y en la mencionada localidad de Loughor (Lloyd-Morgan, 1997, n. 114). Si seguimos comparando el panorama hispano y britano, nos encontramos con otra significativa coincidencia. Hasta ahora, todas las evidencias britanas que hemos mencionado se refieren, sobre todo, a armaduras "Newstead", pero al igual que sucede en León, Britania también cuenta con ejemplares tardorromanos de la clase "Corbridge". Valga citar, a título de ejemplo, los discos repujados adscritos a esta última categoría de corazas documentados en contextos del siglo IV de Segontium (Allason-Jones, 1993, n. 129) y Caerleon (Webster, 1992, n. 136), hallazgos cuya cronología ha pasado inadvertida en los estudios sobre loricae segmentatae realizados hasta el presente.

No debe sorprendernos la idea de que las armaduras segmentadas continuaron en uso durante el Bajoimperio, pues otros elementos característicos de las corazas de la tercera centuria sobrevivieron durante los inicios de la época tardorromana. Un buen ejemplo de ello son los pectorales repujados utilizados en las corazas de escamas y en las loricae segmentatae del tipo "Alba Iulia". Anteriormente ya expusimos el ejemplar de León datado en el siglo IV, pero a él habría que añadir todo un elenco de piezas descubiertas en Britania, entre otros lugares, nuevamente en Caerleon (Webster, 1992, 106). No obstante, los especímenes britanos habían pasado desapercibidos hasta el momento, debido a que el hallazgo más habitual vinculado a estos elementos son los pasadores ornamentados con bustos de "Marte" que sujetan la chapa a la coraza, los cuales a menudo son publicados como meros apliques decorativos para muebles. El hallazgo del pectoral leonés (fig. $8,1)$, que conserva uno de estos apliques aún adherido a la placa, pone de manifiesto algo desconocido hasta ahora, el que estas piezas formaban parte en realidad del equipo militar, dato que ya se vislumbraba debido a sus similitudes formales con las anillas que abrochaban 
las armaduras "Newstead", pues lo único que las diferencia es la sustitución del terminal anillado por un motivo figurado.

Una vez concluido el apartado cronológico, queremos hacer hincapié en otro aspecto derivado de nuestro estudio. Los hallazgos hispanos también cuestionan uno de los principios básicos más extendidos sobre las armaduras segmentadas. La teoría de que las distintas variantes no son más que evoluciones de un tipo que deriva en otro, por lo que se sucederían en el tiempo sin apenas solapamiento temporal. Pero en Hispania este axioma no se cumple, pues los distintos tipos conviven durante mucho tiempo, como podemos comprobar claramente en la línea temporal que los caracteriza (fig. 10). En concreto, los tipos "Corbridge" y "Newstead" comparten en los yacimientos de León casi toda su vida, casi dos siglos de convivencia. Hasta el presente solo se había constatado la coexistencia de las dos variantes mencionadas durante un breve periodo de tiempo, centrado en la primera mitad del siglo II, así el hallazgo trajano-adrianeo de Carlisle (McCarthy et al, 2001, 507-8) y el más dudoso antonino del Waffenmagazin de Carnuntum (Von Groller, 1901a; 1901b). Tradicionalmente se ha justificado esta coexistencia esporádica por tratarse de una fase transicional, en la que coincidirían los momentos finales de uso de la categoría "Corbridge" y los inicios de la "Newstead". No obstante los hallazgos hispanos ponen en tela de juicio tal interpretación y abren nuevas perspectivas, sobre todo si tenemos en cuenta que están acompañados por otros testimonios britanos, los cuales habían sido hasta ahora desestimados, como la aparición de armaduras "Corbridge" en contextos del siglo IV de las Islas Británicas. Con esto no queremos decir que debamos desechar totalmente la hipótesis evolutiva, si no que debemos matizarla en función de los nuevos descubrimientos. Con los datos actuales podemos asegurar que cada nuevo tipo no implicó el que se desechara totalmente el precedente, al menos en lo que concierne a las dos categorías más longevas, los tipos "Corbridge" y "Newstead".

\section{CONCLUSIONES}

A través de estas páginas hemos ido dotando de un marco cronológico y comparativo a los abundantes restos de armaduras segmentadas descubiertos en la zona leonesa, testimonios que ponen en tela de juicio la temporalidad que hasta ahora se había señalado para este tipo de piezas. Precisamente la extensa secuencia temporal de los hallazgos permite cuestionar hipótesis ampliamente representadas en los estudios sobre armaduras segmentadas efectuados hasta el presente, como la teoría evolutiva que postula una escasa convivencia de las distintas categorías.
Desde el punto de vista de la arqueología hispanorromana, los diversos descubrimientos nos permiten realizar una serie de reflexiones centradas en la dispersión espacial y las implicaciones histórico-arqueológicas que denota. La localización en nuestro territorio durante época tardorromana de un elemento tan característico del equipo militar legionario, como es la lorica segmentata, supondría la plena operatividad de la legio VII hasta fechas avanzadas de la cuarta centuria. Las corazas segmentadas no solo se documentan en el campamento principal de dicha legión en León, sino también en yacimientos circundantes, como Astorga, Puente Castro y Lancia lo que demostraría la presencia militar en los mismos. Dicha presencia se hizo patente en el último tercio del siglo III, momento en que la vida militar de nuestra región se activa, con la movilidad de efectivos humanos y el refuerzo del sistema defensivo. Este dinamismo debe estar en consonancia con los sucesos históricos del momento, los cuales fueron de magnitud suficiente como para dar un giro a la tranquila existencia de los legionarios hispanos. No obstante en la actualidad no podemos establecer las causas exactas que lo motivaron, si bien hemos señalado cómo la inestabilidad originada con el Imperio Gálico pudo hacer replantear al Estado Romano la seguridad de esta zona. Astorga no solo proporciona materiales de los inicios del Imperio, ligados a la fase campamental de la legio $X$ previa a la urbe, sino también ejemplares tardíos. Entre ellos, el descubrimiento de armaduras datadas en el tránsito entre la tercera y la cuarta centuria, podría incluso avalar, a nuestro juicio, la intervención del ejército, y concretamente de la legio VII, en la construcción de la muralla bajoimperial de la ciudad.

\section{BIBLIOGRAFÍA}

ALLASON-JONES, I., 1993: "Small finds". En Casey, PJ, Davies, JL y Evans, J., 1993, 165-210.

ALLASON-JONES, L. 1996: "Roman military and domestic artefacts from Great Chesters". Archaeologia Aeliana ser.5, 24, 187-214.

AURRECOECHEA FERNÁNDEZ, J., 2006a: “Talleres dedicados a la producción de equipo militar en los campamentos romanos de León, con especial referencia a los restos de lorica segmentata". Arqueología Militar Romana en Hispania II. Producción y abastecimiento en el ámbito militar. León, 309-334.

AURRECOECHEA FERNÁNDEZ, J., 2006b: "Roman military equipment in Spain". The Roman army in Hispania. An archaeological guide. León, 167-180.

AURRECOECHEA, J.; GARCÍA, V., 2006: "Un pectoral de armadura con decoración repujada, hallado en el campamento de la Legio VII en León". Sautuola, $12,112-119$. 
BALENT, M., 1989: The Compendium of Weapons, Armor, and Castles. Michigan.

BISHOP, M. C., 2002: Lorica segmentata, Vol. I: A handbook of articulated Roman plate armour, Braemar.

BISHOP, M.C.; COULSTON, J.C., 1993: Roman Military Equipment from the Punic Wars to the Fall of Rome, London.

BRAILSFORD, J.W. 1962: Hod Hill 1: Antiquities from Hod Hill in the Durden Collection, London.

BRYANT, S. et alii, 1986: Roman Manchester: a frontier settlement, Manchester.

CARNAP-BORNHEIM, C. VON, 1991: Die Schwertriemenbügel aus dem Vimose (Fünen). Zur Typologie der Schwertriemenbügel der römischen Kaiserzeit im Barbarikum und in den römischen Provinzen, Kleine Schriften aus dem Vorgeschichtlichen Seminar Marburg, 38, Marburg.

CARUANA, I. 1993: "A third century lorica segmentata back-plate from Carlisle". Arma, 5, 15-18.

CASEY, PJ, DAVIES, JL Y EVANS, J., 1993: Excavations at Segontium. (Caernarfon) Roman fort 1975-1979. London.

CONNOLLY, P., 1991: "The Roman fighting technique deduced from armour and weaponry". En Maxfield ; Dobson, 1991, 358-63.

COULSTON, J.C., (ed.), 1988: Military Equipment and the Identity of Roman Soldiers. Proceedings of the Fourth Roman Military Equipment Conference. BAR International Series, 394, Oxford.

CURLE, J., 1911: A Roman Frontier Post and its People. The Fort at Newstead, Glasgow.

DEIMEL, M., 1987: Die Bronzekleinfunde vom Magdalensberg. Klagenfurt.

DESCHLER-ERBS, E., 1999: Ad arma! Römisches Militär des 1. Jahrhunderts n. Chr. in Augusta Raurica. Augst.

EIBNER, C., 2000: "Ein römischer Spangenpanzer aus Stillfried an der March". Archäologie Österreichs, 11, 32-34.

DOWN, A., 1989: Chichester Excavations 6, Chichester.

EIBNER, C., 2000: "Ein römischer Spangenpanzer aus Stillfried an der March". Archäologie Österreichs, $11,32-34$.

EVANS, D.R., 2000: The Caerleon canabae: excavations in the civil settlement 1984-90. Britannia Monograph Series, 16, London.

FERNÁNDEZ IBÁÑEZ, C., 1994: "Un castrum legionis en Herrera de Pisuerga (Palencia)". O Rumor da Fraga, 7, 11-14.

FERNÁNDEZ IBÁÑEZ, C.; PÉREZ, C.; ILLARREGUI, E., 1996: "Breve avance sobre as últimas investigacións levadas a cabo en Pisoraca e no seu campamento lexionario". Larouco, 2, 77-87.
FILLOY, I. Y GIL, E., 2000: La romanización en Álava. Catálogo de la exposición permanente sobre Álava en época romana del Museo Arqueológico de Álava. Vitoria.

FINGERLIN, G., 1986: Dangstetten I. Katalog der Funde (Fundstelle 1 bis 603). Forschungen und Berichte zur Vor- und Frühgeschichte in BadenWürttemberg, 22, Stuttgart.

FOX, A., 1940: "The legionary fortress at Caerleon. Excavations at Myrtle Cottage Orchard, 1939". Archaeologia Cambrensis, 95, 101-52.

FRANZIUS, G., 1995: "Die römischen Funde aus Kalkriese 1987-95 und ihre Bedeutung für die Interpretation und Datierung militärischer Fundplätze der augusteischen Zeit im nordwesteuropäischen Raum". Journal of Roman Military Equipment Studies, 6, 69-88.

GARBSCH, J., 1978: Römische Paraderüstungen. München.

GARCÍA-BELLIDO, M. ${ }^{\mathrm{a}}$ P. (coord.), 2006: Los campamentos romanos en Hispania (27 a. C.-192 d. C.). El abastecimiento de moneda. Anejos de Gladius 9, CSIC, Madrid.

GARCÍA DÍEZ, F., 1999: "Algunas piezas metálicas romanas de Herrera de Pisuerga". Papeles Herrerenses, 2, 13-31.

GROLLER, M. VON, 1901a: "Das Lager von Carnuntum". Der Römische Limes in Österreich, 2, 15-84.

GROLLER, M. VON, 1901b: 'Römische Waffen', Der Römische Limes in Österreich 2, 85-132.

HARMAND, J., 1986: "L'armament défensif romain de metal dans le nord-ouest de l'empire, de la conquête au Ve siècle". Caesarodunum, 22, 189-203.

HARTLEY, B.R., 1972: "The Roman occupation of Scotland: the evidence of Samian ware". Britannia, $1,1-55$.

HAWKES, C.F.C.; HULL, M.R., 1947: Camulodunum. First Report on the Excavations at Colchester 19301939. Oxford.

JAMES, S., 2004: The excavations at Dura-Europos conducted by Yale University and the French Academy of Inscriptions and Letters 1928 to 1937. Final Report VII: The arms and armour and other military equipment. The British Museum Press. Londres.

KLUMBACH, H., (1962): "Römische Panzerbeschläge aus Manching", Festschrift Wagner. Schriftenreihe zur Bayerischen Landesgeschichte, 62.

LLOYD-MORGAN, G., 1997:'Objects of cooper alloy and silver". En Marwell \& Owen-John, 1997, 234-73.

MARVELL, A.G., 1996: "Excavations at Usk 19861988”. Britannia, 27, 51-110.

MARWELL, A.G.; OWEN-JOHN, J., 1997: Leucarum. Excavations at the Roman Auxiliary Fort at Loughor, West Glamorgan 1982-84 and 1987-88. Britannia Monograph Series, 12. London. 
MAXFIELD, V.A.; DOBSON, M.J., (eds.) 1991: Roman Frontier Studies 1989. Exeter.

MCCARTHY, M., 1990: A Roman, Anglian and Medieval Site at Blackfriars Street, Carlisle, Excavations 1977 79. Cumberland and Westmorland Antiquarian and Archaeological Society Research Series, 4, Kendal.

MCCARTHY, M.; BISHOP, M.C.; RICHARDSON, T., 2001: "Roman armour and metalworking at Carlisle, Cumbria, England”. Antiquity, 75, 507-508.

MORILLO, A., 1999: Lucernas romanas en la región septentrional de la Península Ibérica. Contribución al conocimiento de la implantación romana en Hispania. Monographies Instrumentum 8, Montagnac.

MORILLO, A.; GARCÍA, V., 2006: "Legio (León): cronologías estratigráficas”. En García-Bellido, Ma P. (coord.), 2006, 244-257.

NEWSTEAD, R., 1939: "Records of archaeological finds, Hunter Street site on the Odeon Theatre". Journal of Chester Archaeological Society, 33, 49-63.

OLDENSTEIN, J., 1976: "Zur Ausrüstung römischer Auxiliareinheiten". Bericht der Römisch-Germanischen Kommission, 57, 49-284.

PÉREZ GONZÁLEZ, C., 1996: "Asentamientos militares en Herrera de Pisuerga". Coloquio Internacional sobre los Finisterres Atlánticos en la Antigüedad. Época Prerromana y Romana, Gijón, 91-102.

PETCULESCU, L., 1990: "Contributions to Roman decorated helmets and breastplates from Dacia". Akten des 14. Internationalen Limeskongresses 1986 in Carnuntum. Vienna, 843-54.

POULTER, A.G., 1988: “Certain doubts and doubtful conclusions: the lorica segmentata from Newstead and the Antonine garrison". En Coulston, J.C., 1988, 31-49.

REINECKE, P., 1927: "Römische und frühmittelalterliche Denkmäler vom Weinberg bei Eining a.d. Donau". En Festschrift zur Feier des Funfundsiebzigjhärigen Bestehens des Römisch-Germanischen Central-Museums zu Mainz, Mainz, 157-70.

RICHARDSON, T., 2001: "Preliminary thoughts on the Roman armour from Carlisle". Royal Armouries Yearbook 6, Cambridge, 186-189.
ROBINSON, H.R., 1975: The Armour of Imperial Rome, London.

ROLLASON, E.C., 1961: Metallurgy for engineers, London.

SCHLÜTER, W., 1992: “Archäologische Zeugnisse zur Varusschlacht? Die Untersuchungen in der Kalkrieser-Niewedder Senke bei Osnabrück. Mit Beiträgen von Fr. Berger, G. Franzius, J. Lienemann, A. Rost, E. Tolksdorf-Lienemann, R. Wiegels, S. WilbersRost". Germania, 70, 307-402.

TEJRAL, J., 1994: "Römische und germanische Militärausrüstungen der antoninischen Periode im Licht norddanubischer Funde". En Carnap-Bornheim, C., 1994, 27-60.

THOMAS, M.D., 2003: Lorica segmentata, Vol. II: A catalogue of finds, Braemar.

THOMPSON, F.H., 1962: "Infirmary Field excavations 1957”. Journal of Chester Archaeological Society, 49, 1-3.

UNZ, C.; DESCHLER-ERB, E., 1997: Katalog der Militaria aus Vindonissa. Militärische Funde, Pferdegeschirr und Jochteile bis 1976, Veröffentlichungen der Gesellschaft Pro Vindonissa Bd.14, Brugg.

VICIC, B., 1999: "Die frührömische Fabrica vom Gornji trg 3 in Ljubljana”, Instrumentum, 10, déc. 1999, 15 y 31.

WEBSTER, G., 1953: "Excavations on the legionary defences at Chester 1942-52 (part II)". Journal of Chester Archaeological Society, 40, 1-23.

WEBSTER, G., 1958: "The Roman military advance under Ostorius Scapula”. Archaeological Journal, 105, 49-98.

WEBSTER, J., 1992: "The objects of bronze". Roman Gates Caerleon. Oxbow Monograph, 15, Oxford.

ZIENKIEWICZ, J.D., 1986: The Legionary Fortress Baths at Caerleon. Vol.2 The Finds, Cardiff.

Recibido el 11-04-07

Aceptado el 17-07-07 